\title{
Computational Modeling of Desiccation Properties (CW, LS, and VS) of Waste-Based Activated Ash-Treated Black Cotton Soil for Sustainable Subgrade Using Artificial Neural Network, Gray-Wolf, and Moth-Flame Optimization Techniques
}

\author{
Kennedy C. Onyelowe $\mathbb{D}^{1},{ }^{1}$ Jamshid Shakeri, ${ }^{2}$ Hasel Amini-Khoshalan, ${ }^{3}$ \\ Thompson F. Usungedo, ${ }^{4}$ and Mohammadreza Alimoradi-Jazi ${ }^{5}$ \\ ${ }^{1}$ Department of Mechanical and Civil Engineering, Kampala International University, Kampala, Uganda \\ ${ }^{2}$ Department of Mining Engineering, Hamedan University of Technology, Hamedan, Iran \\ ${ }^{3}$ Department of Mining Engineering, University of Kurdistan, Sanandaj, Iran \\ ${ }^{4}$ Department of Civil Engineering, Michael Okpara University of Agriculture, Umudike, Nigeria \\ ${ }^{5}$ Department of Computer Engineering, K. N. Toosi University of Technology, Tehran, Iran \\ Correspondence should be addressed to Kennedy C. Onyelowe; kennedychibuzor@kiu.ac.ug
}

Received 16 November 2021; Revised 31 January 2022; Accepted 5 February 2022; Published 27 February 2022

Academic Editor: Antonio Caggiano

Copyright ( $\odot 2022$ Kennedy C. Onyelowe et al. This is an open access article distributed under the Creative Commons Attribution License, which permits unrestricted use, distribution, and reproduction in any medium, provided the original work is properly cited.

\begin{abstract}
Artificial neural network (ANN), gray-wolf, and moth-flame optimization (GWO and MFO) techniques have been used in this research work to predict the effect of activated sawdust ash (ASDA) on the crack width (CW), linear shrinkage (LS), and volumetric shrinkage (VS) of a black cotton soil utilized as a subgrade material. Problematic soils or black cotton soils are not good pavement foundation materials except that they are pretreated in order to meet the basic strength characteristics required for roads in Nigeria. Due to this reason, there has been ongoing research to evaluate the best practices in which black cotton soils can be favorably utilized in earthwork construction. On the other hand, there is a huge concern on the solid waste management system in the wood processing environment and the recycling of sawdust into ash and its reuse as an alternative binder has offered a sustainable disposal system. The work tries to use AI-based techniques to predict the crack and shrinkage behaviors of BCS treated with saw dust ash activated with alkali materials. There was appreciable improvement in the shrinkage and crack parameters over the 30-day drying period due to the addition of ASDA. The intelligent model results showed that the three techniques successfully predicted the CW, LS, and VS with a performance accuracy above $90 \%$, while ANN produced the minimal error in performance outperforming the other techniques. Sensitivity study showed that the drying time $(T)$ was the most influential of the studied parameter. Hence, soil stabilization has shown its potential system of waste management in the wood processing industry.
\end{abstract}

\section{Introduction}

The swell-shrink cycle is a phenomena exhibited by black cotton soils and other problematic soils when exposed to moisture either as a foundation material subjected hydraulically bound conditions or a superstructural material exposed to moisture ingress through suction or migration from runoff. Due to this behavior, black cotton soils do not support foundation loads except they are pretreated to meet the minimum requirement for pavement subgrade. The handling and utilization of BCS is a worrisome procedure due to the erratic and unpredictable state of the soils. There have been successful stabilization procedures recorded with the use of BCS and agroindustrial-based waste materials added as cementing admixtures in a soil stabilization protocol [1]. However, there seems to be a serious concern due to multiple visits to the laboratory to generate data needed for earthwork designs and construction as well as 
infrastructure performance evaluation exercise [2]. In order to overcome these challenges which also include the need for sophisticated laboratory equipment, there has been the deployment of smart and intelligent techniques based on the algorithms of AI-based predictive modeling in geotechnics and materials engineering. These AI-based techniques forecast engineering problems for use in future exercise to predict and to monitor the performance of built infrastructure. In addition to the AI-based techniques, e.g., ANN, GP, GEP, and EPR, there are also baseline regression methods like LMR or MLR, Pearson Regression, etc., which help to present the statistical analysis of multiple data collected for engineering analysis $[1,2]$. However, a group of methods have not been commonly used in the field of geosciences like gray-wolf optimization (GWO) and mothfly optimization (MFO) algorithms. These novel methods are being applied in this research work in addition to artificial neural network (ANN) and linear multivariate regression (LMR) analysis to predict crack width, linear, and volumetric shrinkages of HSDA-treated BCS utilized as a subgrade material.

One of the most successful methods used to predict variance in distance dependence based on the linear composition of independent distance variables, dual or artificial, which was used by Pearson in 1908 is linear multivariate regression (LMR). The generalization of simple linear regression to more than one independent variable and a specific case of general linear models is limited to one dependent variable (Shakeri et al. 2020; [3]; Amini et al. 2021). Therefore, the general goal of this method is to obtain more information about the relationship between several independent or predictor variables and a dependent variable or criterion. The mentioned cases have led to the widespread use of this method to approximate problems in the field of engineering [3-6]; Amini et al., 2021; Monjezi et al., 2021). In this study, the dependent variables include Crack Width (CW), Volumetric Shrinkage (VS), and Linear Shrinkage (LS), which may depend on $n$ independent variables $(x)$. In general, a typical multiple regression formula is presented in the following format:

$$
C=\beta_{0}+\beta_{1} x_{1}+\cdots+\beta_{n} x_{n}+\varepsilon,
$$

where $\varepsilon$ error of the model; $j=0,1, \ldots, n$ and $\beta_{j}$ are the regression coefficients (Amini et al., 2021; Shakeri et al., 2020; [4]; Montgomery, 1992; [3]).

The gray-wolf algorithm, which is inspired by the natural life and hunting process of gray wolves, can be used to solve complex optimization problems. This algorithm has been proposed by Mirjalili et al. and has been used in many engineering issues [7-10]. Gray wolves have a social hierarchy, all of which are divided into four categories based on their objective values [11]; Mirjalili et al. 2014; [12,13]. The responsibility for decision-making (such as hunting and sleeping) rests with the leader of the wolf alpha group (a), and the second group that assists the alpha group in decision-making is the wolf beta $(\beta)$ commanders. The subordinates of delta wolves $(d)$ and in the lowest rank omega wolves (?) are those who follow the instructions of the dominant wolves $(\alpha, \beta$, and $\delta)$ in the evolution of the algorithm (see Figure 1). According to Figure 2, to update the position of wolves in the search space, you can see the position of wolves and prey and the parameters in the equations used (in (2)-(6)). According to studies (Mirjaliliili et al. 2014; Xu $t$ al. 2020; [13-15]) the gray-wolf algorithm uses siege, hunt, attack, and recovery steps to hunt prey.

For this purpose, the following mathematical representation is defined to mimic the siege behavior of gray wolves:

$$
\begin{aligned}
\vec{D} & =\left|\vec{C} \cdot \vec{X}_{p}(t)-\vec{X}(t)\right| \\
\vec{X}(t+1) & =\vec{X}_{p}(t)-\vec{A} \cdot \vec{D}
\end{aligned}
$$

In these relations, $t$ indicates the common repetition, $\vec{X}_{p}$ represents the prey position vector, and $\vec{X}$ represents the gray-wolf position vector. $\vec{A}\left(\vec{A}=2 \vec{a} \cdot \vec{r}_{1}-\vec{a}\right)$ and $\vec{C}$ $\left(\vec{C}=2 \cdot \vec{r}_{2}\right)$ are coefficient vectors and are calculated from the following equations (Mirjalili et al., 2014).

In this regard, the vector $\vec{a}$ decreases from 2 to 0 during different iterations and the $\vec{r}_{1}$ and $\vec{r}_{2}$ vectors are random vectors in $[0,1]$. In GWO, it is assumed that alpha, beta, and delta wolves have better knowledge of the possible location of prey (Mirjalili et al., 2014). Therefore, omega wolves must update their positions according to alpha, beta, and delta as follows:

$$
\vec{D}_{\alpha}=\left|\vec{C}_{1} \cdot \vec{X}_{\alpha}-\vec{X}\right| \cdot \vec{D}_{\beta}=\left|\vec{C}_{2} \cdot \vec{X}_{\beta}-\vec{X}\right| \cdot \vec{D}_{\delta}=\left|\vec{C}_{3} \cdot \vec{X}_{\delta}-\vec{X}\right|,
$$

$$
\vec{X}_{1}=\vec{X}_{\alpha}-\vec{A}_{1} \cdot\left(\vec{D}_{\alpha}\right) \cdot \vec{X}_{2=} \vec{X}_{\beta}-\vec{A}_{2} \cdot\left(\vec{D}_{\beta}\right) \cdot \vec{X}_{3}=\vec{X}_{\delta}-\vec{A}_{3} \cdot\left(\vec{D}_{\delta}\right)
$$

$$
\vec{X}(t+1)=\frac{\vec{X}_{1}+\vec{X}_{2}+\vec{X}_{3}}{3}
$$

As shown by the algorithm trend in Figure 3, when all the wolves are moved (one iteration), the wolves (solutions) are reevaluated using the target function. The top three solutions become $\alpha, \beta$, and $d$ wolves, while the other wolves must update their position in the next iteration. These steps are repeated until the stop criterion is reached. The detail formulation of the GWO can be found in the literature (Mirjalili et al., 2014; Xu et al., 2020; [13]; Emary et al., 2020; [9]).

MFO is a swarm optimization algorithm based on the method of moving propellers (transverse direction) in nature. This algorithm is introduced by Mirjalili [17]. In MFO, the butterfly flies at a constant angle to the moon, and when a human creates artificial light, the butterflies see it and try to maintain the same angle with that light and fly in a straight line. Because such light is so close to the moon, maintaining the same angle as the light source creates an unhelpful or deadly spiral flight path for the butterflies (Figure 4). The initial, repeat, and stop criteria form the general framework of the MFO [17-20]. 


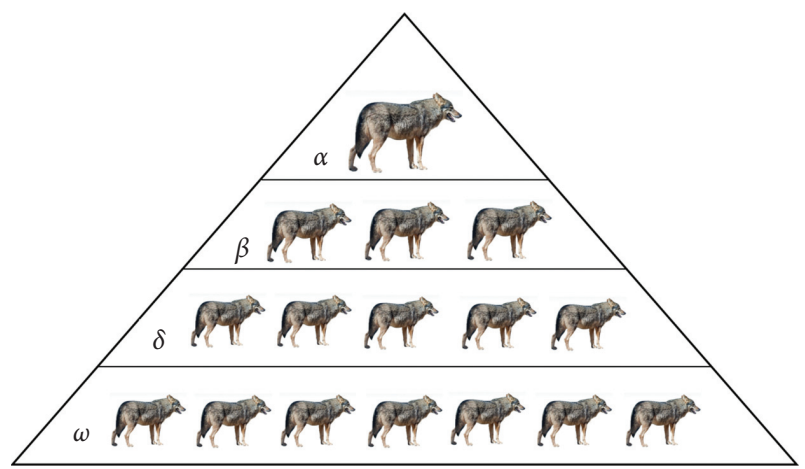

FIGURE 1: The social hierarchy of gray wolves [13].

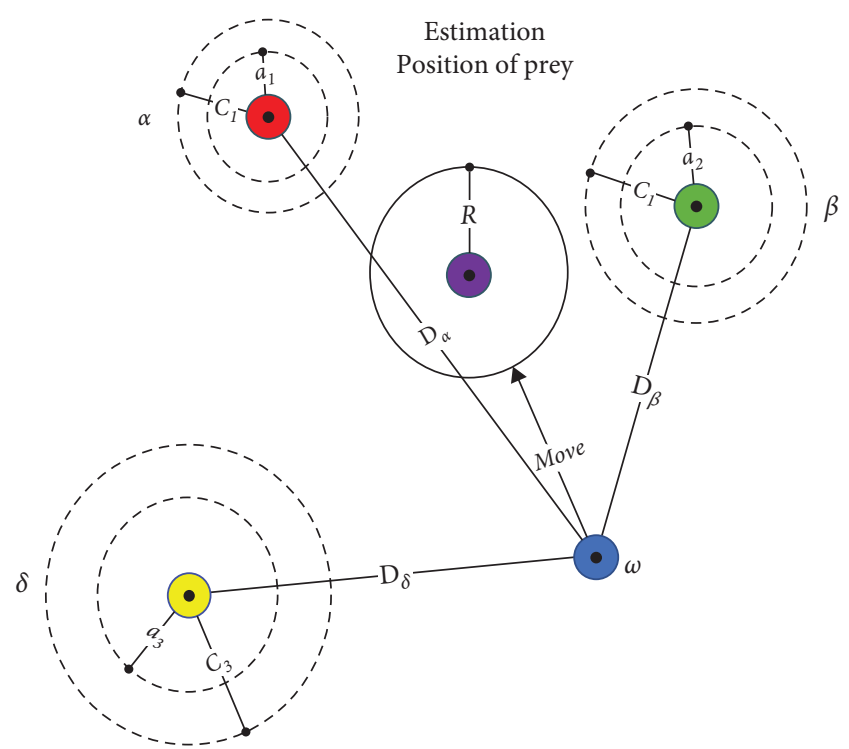

FIgURe 2: The position update process of the gray-wolf algorithm (Mirjalili et al., 2014).

In the first stage, a population of butterflies is randomly generated by the MFO and calculates their appropriateness values. In the second stage, which is the iteration stage, the main function is performed and the butterflies move in the search space. In the third step, if the stop criterion is met, it returns correctly (see Figure 5). Conversely, if the stop criterion is not met, an incorrect item will be returned. As well as, the main method of updating the butterfly search space is the logarithmic helix [21-23].

Use (4) to update the position of each moth and simulate the flight mode of the moth.

$$
M_{i}=D_{i} e^{b t} \cdot \operatorname{Cos}(2 \pi t)+F_{j},
$$

where $\mathrm{D}_{i}$ refers to the space between the $\mathrm{i}$-th moth and the $\mathrm{j}$-th flame $\left(D_{\mathrm{i}}=\mathrm{G}_{\mathrm{i}}-\mathrm{M}_{\mathrm{i}}\right), b$ indicates a fix to define the shape of the logarithmic spiral, and $t$ indicates a random number between $[-1,1]$. When $t=-1$, it means the distance between flame and moth is the closest, and when $t=1$, it means the distance between them is the maximum. Equation (8) has been adopted to reduce the number of flames during

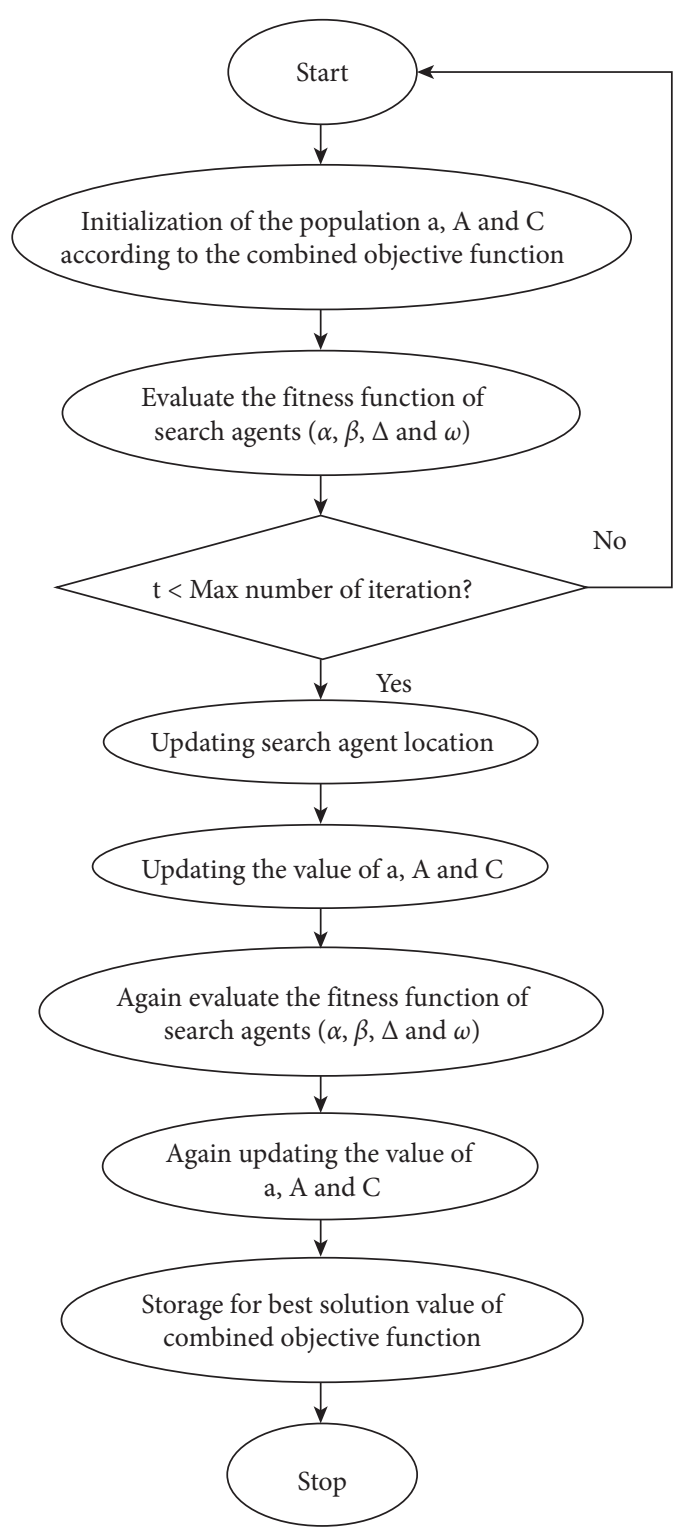

Figure 3: Flowchart of the GWO algorithm [16].

each iteration by an adaptive linear method to improve the local extraction capacity of the moth in the next iteration $[18,19,21,23-25]$ :

$$
\text { flame }=\text { round }\left((\mathrm{N}-1) \frac{(\mathrm{N}-1)}{L}\right),
$$

where $\mathrm{N}$ is the maximum number of flames, $l$ is the current number of iterations, and $T$ indicates the maximum number of iterations. At the beginning of the iteration, the number of flames is $\mathrm{N}$, and the propellers update the position only at the end and around the best flame, which effectively increases the search capability of the MFO algorithm. More information on MFO programs and algorithms can be found in the literature (Mirjalili, 2015; [19-23,25]; Shehab et al., 2020; [24]).

Artificial neural networks inspired by the human nervous system are widely used today in various fields to predict 


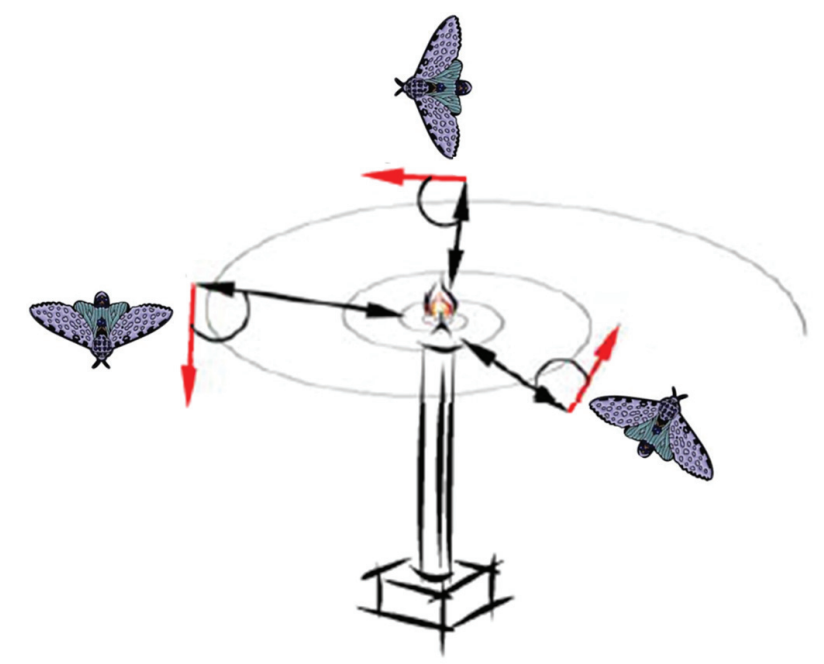

Figure 4: Spiral flying path around close light sources (Mirjalili, 2015).

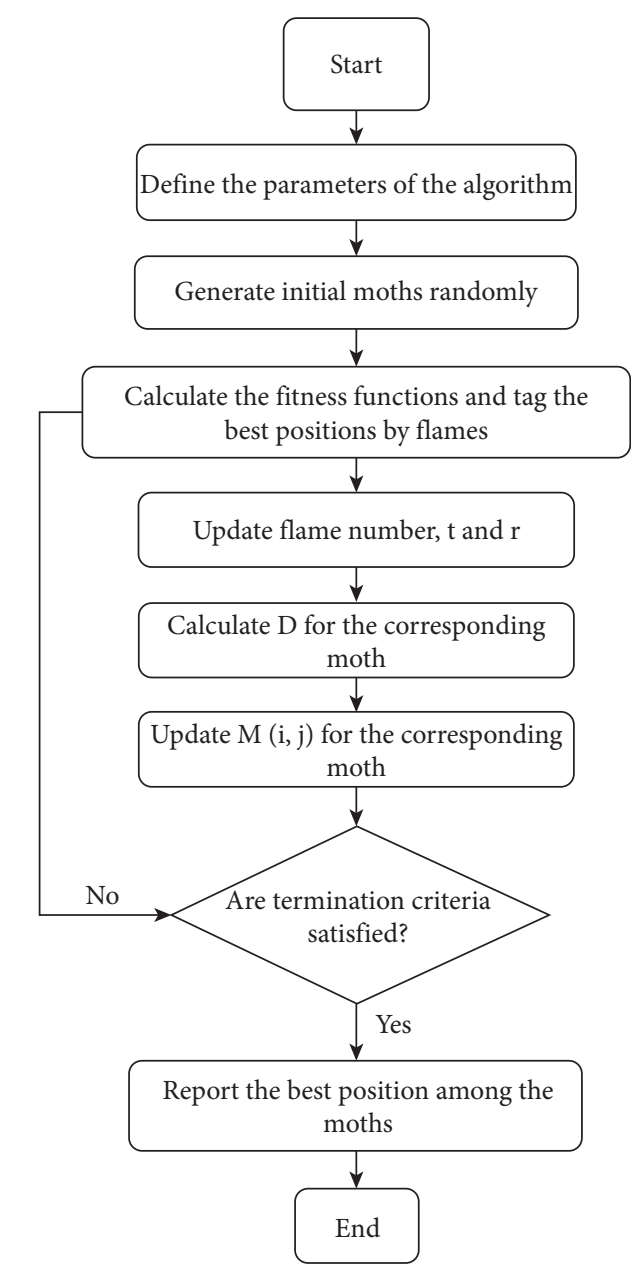

Figure 5: Flowchart of the MFO algorithm (Shehab et al., 2020).

and solve problems (Amini et al., 2021; [26]; Shakeri et al., 2020 ; [27]). One of the most practical types of ANN models includes multilayer perceptron networks that have been used since the 1980s. The structure of these networks typically consists of three types of layers including the input layer, one or more hidden layers, and the output layer. According to existing studies ([3,28]; Amini et al., 2021), the use of only one hidden layer reduces the complexity of the model; however, there is no limit to the choice of the number of layers. Hypothetically, the GWO, MFO, and ANN techniques are more robust than other AI applications in geosciences.

MLP networks usually use different types of activation functions such as tansig, logsig, or purelin. In addition, the Levenberg-Marquardt algorithm is mostly used for network training in the forward-backend publishing process. More details are available in the literature [29,30]; Amini et al., 2021; [3,31,32]; Monjezi et al., 2021; [33].

\section{Materials Preparation and Experimental Methods}

2.1. Materials Preparation. The BCS was collected from Ikem Nvosi located on the coordinates of lat. 6.7799 and long. 7.7148. Figure 6(a) shows the BCS during the sun drying process. The soil was sundried for 5 days and kept in silo bags for use in the experiments. Figures 6(a) and 6(b) show the sawdust and sawdust during combustion to generate sawdust ash (SDA). The sawdust was collected from local wood processing factories at the Timber market where it is indiscriminately disposed, as a result of ineffective waste management system at the market. The scaling and blending of $\mathrm{NaOH}(\mathrm{aq})$ prepared at $8 \mathrm{M}(\mathrm{mol} / \mathrm{L})$ for ecofriendly handling and $\mathrm{NaSiO}_{2}$ to formulate the alkali activator in line with the suggestions of Ashraf et al. [34] were also undertaken and reported by Onyelowe and Usungedo [35]. The two chemicals were mixed in the ratio of $1: 1.5$ liters of the aqueous $\mathrm{NaOH}$ which was produced bearing in mind its molar concentration, which eventually was used to estimate the number of moles of solute. This would not have been possible without determining the mass in grams of the flakes needed to produce 5 liters of the $\mathrm{NaOH}$ in solution bearing in mind its molar mass. With the solution of $\mathrm{NaOH}$, the activator material was formulated and $5 \mathrm{wt} \%$ activator to the SDA was blended deeply with the SDA and allowed for $6 \mathrm{~h}$. The end product of this process was HSDA (a composite binder formulated from biobased industrial solid waste reuse). Finally, the soil, BCS, and the HSDA (which meets the standard specification of ASTM C618 [36] and BS 8615-1 [37]) were stored for use in the stabilization process.

2.2. Experimental Methods. First, preliminary experiments were conducted in accordance with BS1377 [38] for the classification and characterization of test materials and they were particle size distribution (PSD) test, compaction test, Atterberg limits tests, free swell index test, and drying shrinkage test as reported by Onyelowe and Usungedo [35]. The following method was reported by Onyelowe and Usungedo [35]. Furthermore, the HSDA was used in the proportions of $3 \%, 6 \%, 9 \%$, and $12 \%$ by weight of the dry 

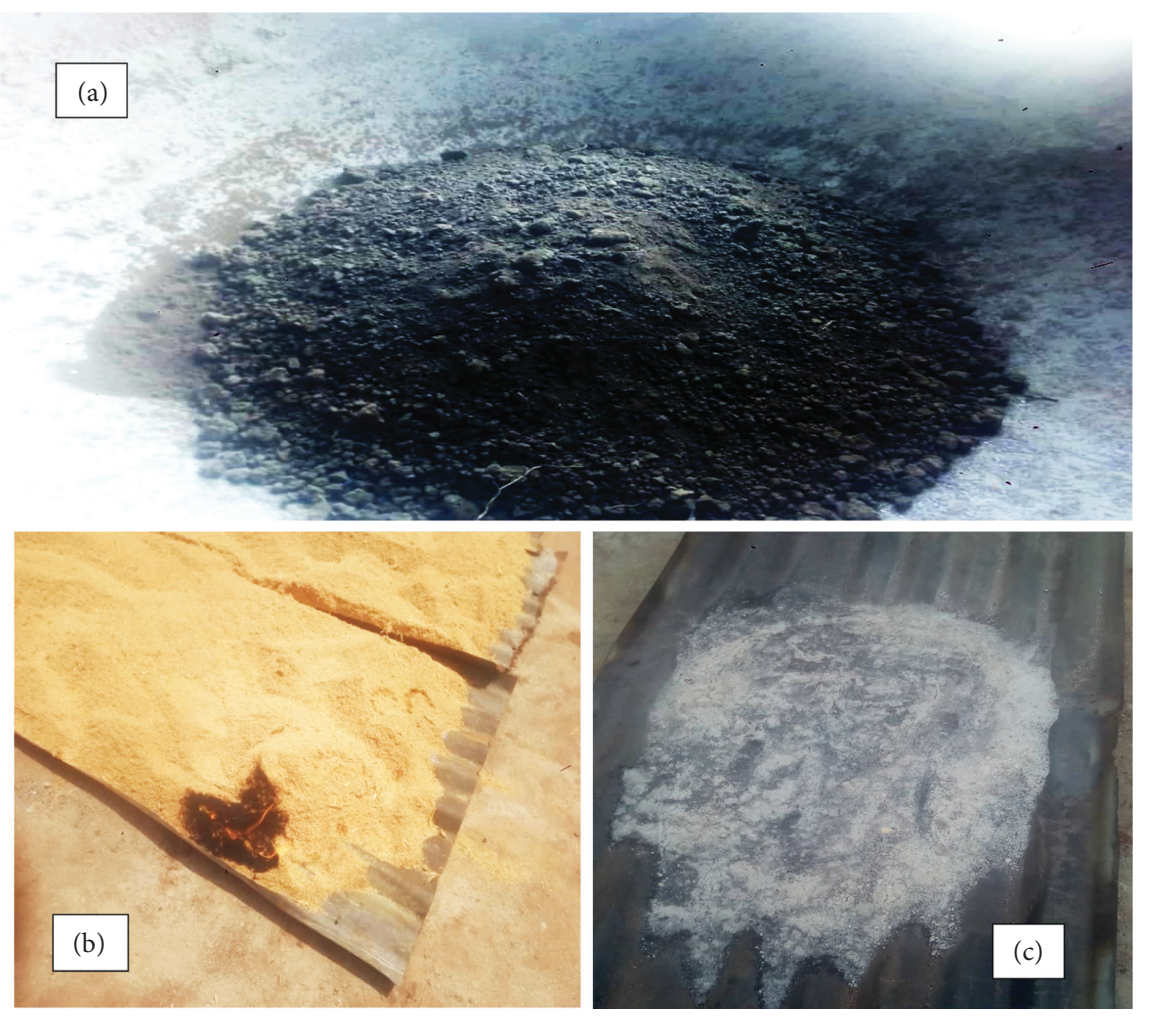

FIGURE 6: Materials preparation: (a) sundried BCS, (b) sundried sawdust (SD), and (c) combusting SD.

sample to treat the BCS. The treated specimens were compacted using the standard proctor mold, extruded as shown in Figure 7, and placed in the oven to dry at $102^{\circ} \mathrm{C}$ for 30 days while the recording of the weight loss, height, and diameter continued for the desiccation duration. The average crack width of the specimens was also recorded using the Digital Vernier Calipers for the pretreated specimens for the 30 days. This stabilization process was conducted based on the requirements of BS1924 [39]. The volume $\left(\mathrm{V}=\mathrm{pi}^{*} \mathrm{R}^{2} \mathrm{H}\right)$, bulk density $(\mathrm{BD}=W / \mathrm{V})$, linear shrinkage $\left(\left(\mathrm{H}_{\mathrm{o}}-\mathrm{H}_{\mathrm{t}}\right) / \mathrm{H}_{\mathrm{o}}\right)$, and volumetric shrinkage $\left(\left(\mathrm{V}_{\mathrm{o}^{-}}\right.\right.$ $\left.\mathrm{V}_{\mathrm{t}}\right) / V_{\mathrm{o}}$ ) were estimated from measured experimental values. The multiple experimental data was collected and tabulated.

2.3. Generated Database and Statistical Analysis. In the present study, based on what is shown in Table 1, a comprehensive statistical indicators database consisting of 155 datasets with three output parameters and six input parameters has been prepared, which in this table shows the range of input and output parameters. Also, in Figure 8 and Table 2, the Pearson correlation for input and output data is shown schematically and in a matrix.

Based on what has been done in previous studies ([3,4]; Monjezi et al., 2021) to find the best statistical relationship between input and output data, the data set was randomly divided into training and validation data. For this purpose, $70 \%$ of the data are considered as validation data and the remaining $30 \%$ as experimental data, and this division is the same for all methods used in this study.

\section{Results and Discussions}

3.1. Materials Characterization. In Figure 9, the particle size distribution of the BCS is presented with a $59.8 \%$ passing sieve number 200 ( $75 \mu \mathrm{m}$ or $0.075 \mathrm{~mm}$ aperture). It can be observed that BCS is poorly graded. Figure 10 shows the propagation of cracks on the drying specimens. Table 3 shows the preliminary properties of the soil with MDD of $1.73 \mathrm{mg} / \mathrm{m}^{3}$ obtained at an OMC of $11.2 \%$; the Atterberg limits behavior of the BCS is presented with LL of $51.8 \%, \mathrm{PL}$ of $16.4 \%$, and PI of $37.7 \%$ (> $17 \%$ ). It can be observed that the CBR is $7.6 \%$ ( $<10 \%$ for subgrade) and the SG is 2.285 . The basic results show that the BCS belongs to an A-7 group of soil in accordance with the AASHTO classification. The soil can also be observed to be highly plastic. With the measured properties, it can be concluded that the BCS is problematic and does not have sufficient properties to be used as a subgrade material in its present condition.

3.2. Predicting with Multiple Linear Regression (MLR). Using the most widely used evaluation criteria in engineering (VAF, $R^{2}$, RMSE, and MAE), the performance of the models obtained in this study is compared in Table 4. Ideally, the RMSE and MAE values should be close to zero and the coefficient of determination $\left(R^{2}\right)$, which is the correlation between the measured and predicted data, close to 1 . Also, the VAF, which shows the difference between the variances, should be close to 1 or $100 \%$. In fact, to find the best result, the four mentioned statistical parameters were selected as the best criteria for LMR, MFO, GWO, and ANN methods. 

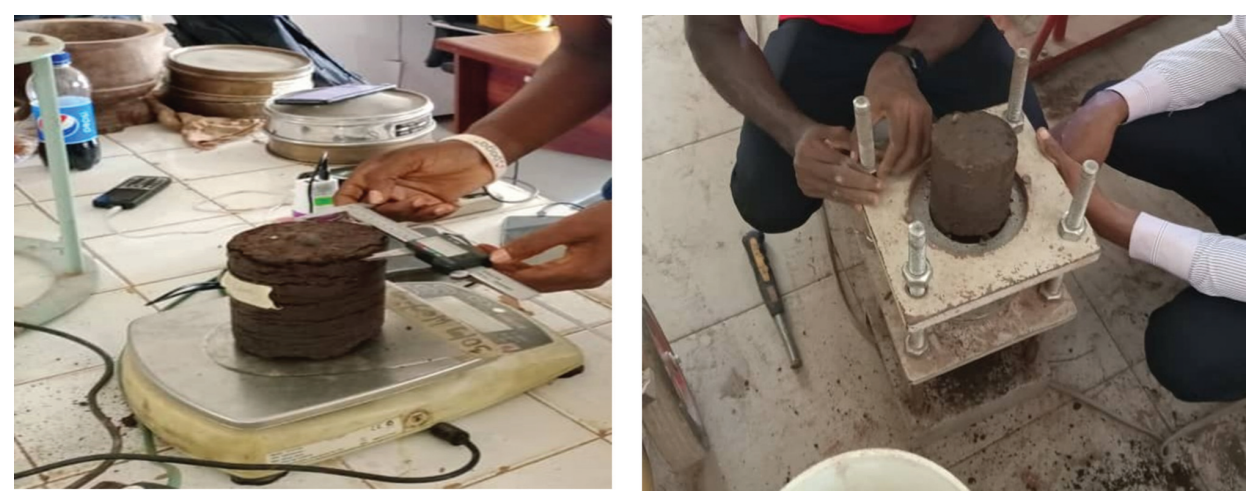

FiguRE 7: HSDA-treated specimen extrusion and measurement.

TABLE 1: Statistical indicators of input and output parameters.

\begin{tabular}{|c|c|c|c|c|c|c|c|c|c|}
\hline \multirow[b]{2}{*}{$\begin{array}{l}\text { Statistics } \\
\text { Symbol }\end{array}$} & \multicolumn{6}{|c|}{ Input } & \multicolumn{3}{|c|}{ Output } \\
\hline & $\begin{array}{l}\text { HSDA } \\
\mathrm{P}(\%)\end{array}$ & $\begin{array}{l}\text { Drying } \\
\mathrm{T} \text { (days) }\end{array}$ & $\begin{array}{l}\text { Wt of spec. } \\
\text { W(kg) }\end{array}$ & $\begin{array}{l}\text { Height } \\
\mathrm{H}(\mathrm{mm})\end{array}$ & $\begin{array}{l}\text { Diameter } \\
\mathrm{D}(\mathrm{mm})\end{array}$ & $\begin{array}{l}\text { Volume } \\
\mathrm{V}(\mathrm{ml})\end{array}$ & $\begin{array}{c}\text { Crack width } \\
\text { CW }(\mathrm{mm})\end{array}$ & $\begin{array}{c}\text { Volumetric shrinkage } \\
\text { VS(\%) }\end{array}$ & $\begin{array}{c}\text { Linear shrinkage } \\
\text { LS(\%) }\end{array}$ \\
\hline Min & 0.00 & 0.00 & 1.00 & 113.70 & 102.54 & 941.00 & 0.00 & 0.00 & 0.00 \\
\hline Max & 12.00 & 30.00 & 1.56 & 115.50 & 105.00 & 1000.20 & 5.91 & 5.92 & 1.56 \\
\hline Mean & 6.00 & 15.00 & 1.17 & 114.63 & 104.07 & 975.41 & 3.91 & 2.48 & 0.74 \\
\hline Std. deviation & 4.26 & 8.97 & 0.16 & 0.60 & 0.69 & 17.78 & 1.36 & 1.78 & 0.51 \\
\hline Variance & 18.12 & 80.52 & 0.03 & 0.36 & 0.47 & 316.15 & 1.85 & 3.17 & 0.26 \\
\hline
\end{tabular}

$$
\begin{gathered}
C W=117.422+(-0.036 P)+(-0.024 T)+(-3.411 W)+(-0.74 H)+(-0.025 V) \\
V S=100.9+(0.001 P)+(-0.001 T)+(-0.003 W)+(0.002 H)+(-0.101 V) \\
L S=99.572+(0.006 P)+(-0.005 T)+(-0.157 W)+(-0.838 H)+(-0.002 V) .
\end{gathered}
$$

Table 3 shows the best values for determining CW, VS, and LS using the MLR, as well as (9)-(11) for outputs predictions. Figure 11 also shows the relationship between measured and predicted output values for test data.

3.3. Predicting with GWO Method. In the first step, to design the GWO, determine the maximum number of repetitions $\left(I_{\max }\right)$ and the number of wolves to achieve the best performance of the GWO model. Therefore, the research was conducted to find the maximum number of optimal replications $\left(I_{\max }\right)$ and the number of wolves, which are listed in Table 5, and the prediction performance of the GWO model was investigated using RMSE. In this method, 70\% (85 data) was used as training data and 30\% (36 data) as test data and validated as presented in Figure 12.

Table 6 shows the results obtained from the optimal GWO model including $R^{2}$, VAF, RMSE, and MAE for data training and testing, which are based on the highest $R^{2}, \mathrm{VAF}$, and the lowest MAE and RMSE. Figure 12 also shows a comparison between measured and predicted outputs values with the GWO model. In addition, the reduction of MSE during the implementation of the GWO process is shown in Figure 13.
3.4. Predicting with MFO Method. As mentioned earlier, in the MFO algorithm, it is assumed that the solutions are candidate for the moths and the variables of the problem are the position of the moths in space. Therefore, moths can fly in one-dimensional, two-dimensional, or three-dimensional space by changing their positional vectors. The difference between them is how they deal with and update each repetition. Flames can be considered flags or pins that are swallowed by moth when searching the search space. Therefore, each moth searches around a flag (flame) and updates it if it finds a better solution. With this mechanism, a moth never loses its best solution (Mirjalili, 2015).

According to what was said in the previous methods, the ratio of $70 \%$ (85 data) was used as educational data and $30 \%$ (36 data) that were randomly selected as test data. Tables 7 and 8 also summarize the MFO network parameters used in the present study to predict outputs and its performance, respectively.

The performance of the best models obtained for predicting outputs (CW, VS, and LS) with the MFO model is shown in Table 7 and the comparison between the measured and predicted values of these models is shown in Figure 14. The reduction of MSE during the MFO process is also shown in Figure 15. 


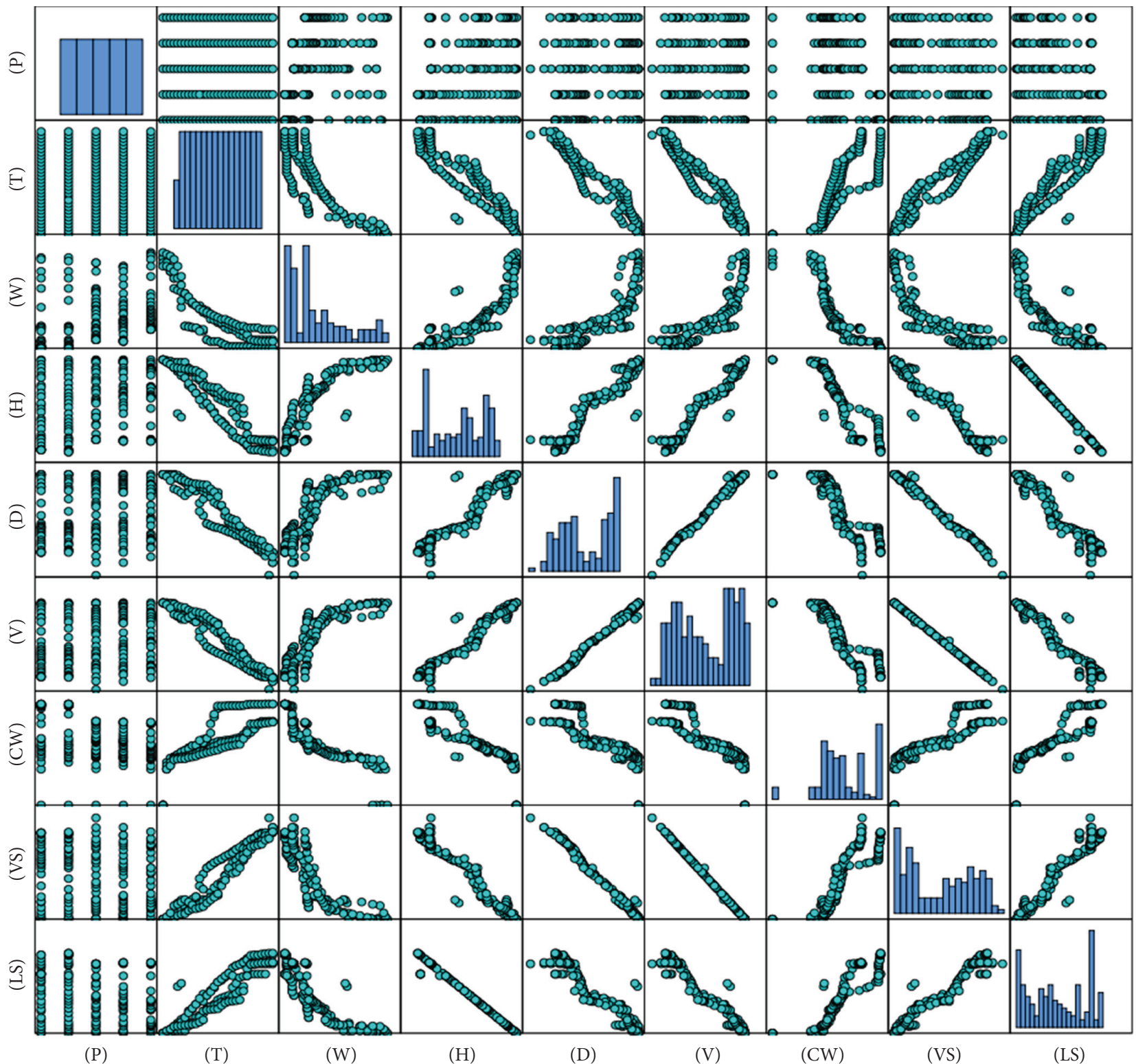

Figure 8: Pearson's schematic linear correlation regression of input and output data.

TABle 2: Pearson's correlation matrix of the input and output variables.

\begin{tabular}{|c|c|c|c|c|c|c|c|c|c|}
\hline Correlations & $\mathrm{P}$ & $\mathrm{T}$ & $\mathrm{W}$ & $\mathrm{H}$ & $\mathrm{D}$ & $\mathrm{V}$ & $\mathrm{CW}$ & VS & LS \\
\hline $\mathrm{P}$ & 1 & 0 & $.303^{* *}$ & $.239^{* *}$ & 0.139 & $.169^{*}$ & $-.367^{* *}$ & $-.166^{*}$ & $-.212^{* *}$ \\
\hline $\mathrm{T}$ & 0 & 1 & $-.841^{* *}$ & $-.930^{* *}$ & $-.954^{* *}$ & $-.957^{* *}$ & $.815^{* *}$ & $.957^{* *}$ & $.926^{* *}$ \\
\hline W & $.303^{* *}$ & $-.841^{* *}$ & 1 & $.860^{* *}$ & $.838^{* *}$ & $.854^{* *}$ & $-.883^{* *}$ & $-.854^{* *}$ & $-.858^{* *}$ \\
\hline $\mathrm{H}$ & $.239^{* *}$ & $-.930^{* *}$ & $.860^{* *}$ & 1 & $.947^{* *}$ & $.973^{* *}$ & $-.892^{* *}$ & $-.972^{* *}$ & $-.992^{* *}$ \\
\hline $\mathrm{D}$ & 0.139 & $-.954^{* *}$ & $.838^{* *}$ & $.947^{* *}$ & 1 & $.996^{* *}$ & $-.854^{* *}$ & $-.996^{* *}$ & $-.942^{* *}$ \\
\hline $\mathrm{V}$ & $.169^{*}$ & $-.957^{* *}$ & $.854^{* *}$ & $.973^{* *}$ & $.996^{* *}$ & 1 & $-.875^{* *}$ & $-1.000^{* *}$ & $-.967^{* *}$ \\
\hline $\mathrm{CW}$ & $-.367^{* *}$ & $.815^{* *}$ & $-.883^{* *}$ & $-.892^{* *}$ & $-.854^{* *}$ & $-.875^{* *}$ & 1 & $.874^{* *}$ & $.881^{* *}$ \\
\hline VS & $-.166^{*}$ & $.957^{* *}$ & $-.854^{* *}$ & $-.972^{* *}$ & $-.996^{* *}$ & $-1.000^{* *}$ & $.874^{* *}$ & 1 & $.966^{* *}$ \\
\hline LS & $-.212^{* *}$ & $.926 \mathrm{v}$ & $-.858^{* *}$ & $-.992^{* *}$ & $-.942^{* *}$ & $-.967 \mathrm{v}$ & $.881^{* *}$ & $.966^{* *}$ & 1 \\
\hline
\end{tabular}

${ }^{* *}$ Correlation is significant at the 0.01 level (2-tailed). ${ }^{*}$ Correlation is significant at the 0.05 level (2-tailed). 


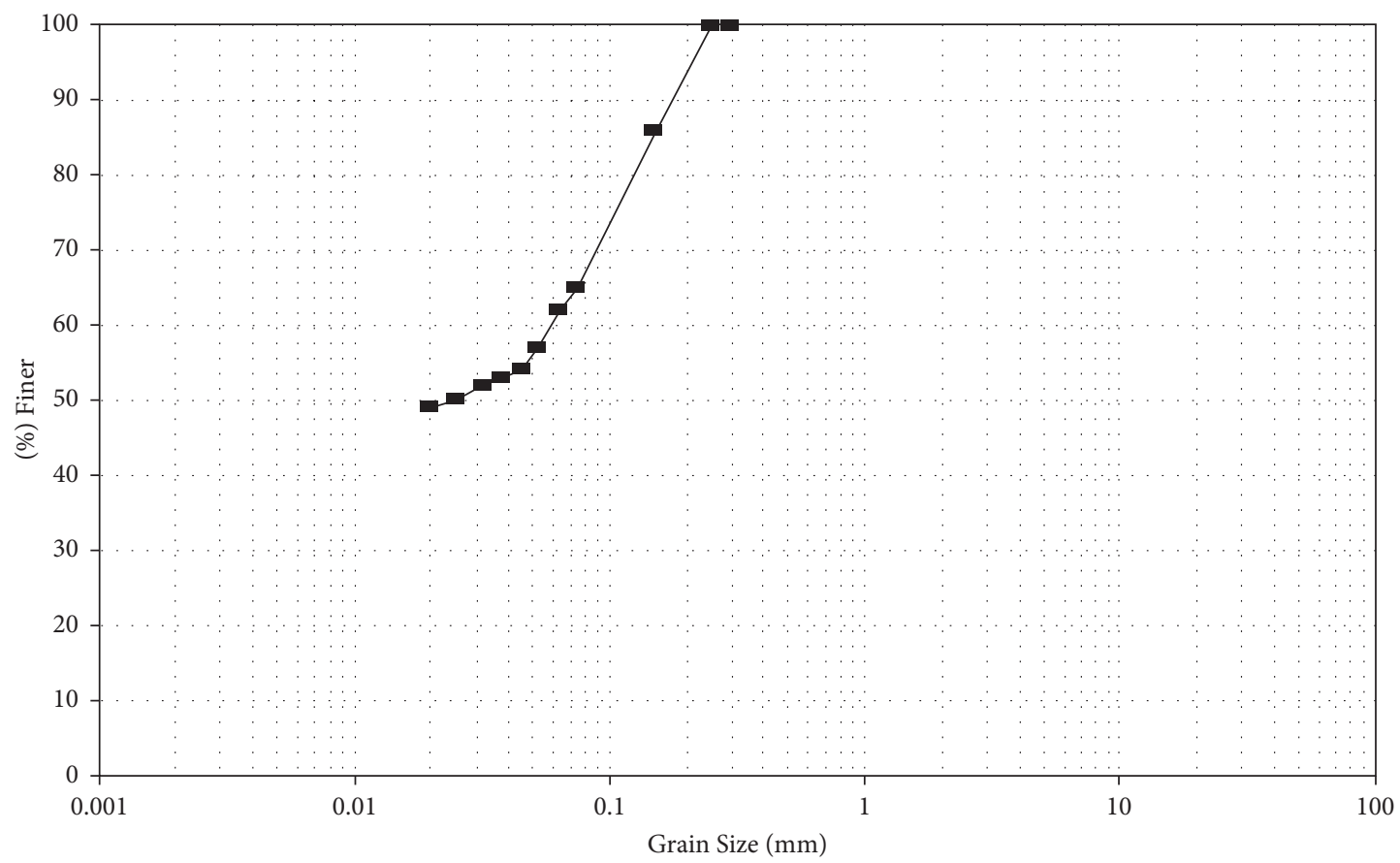

Figure 9: Particle size distribution of BCS.
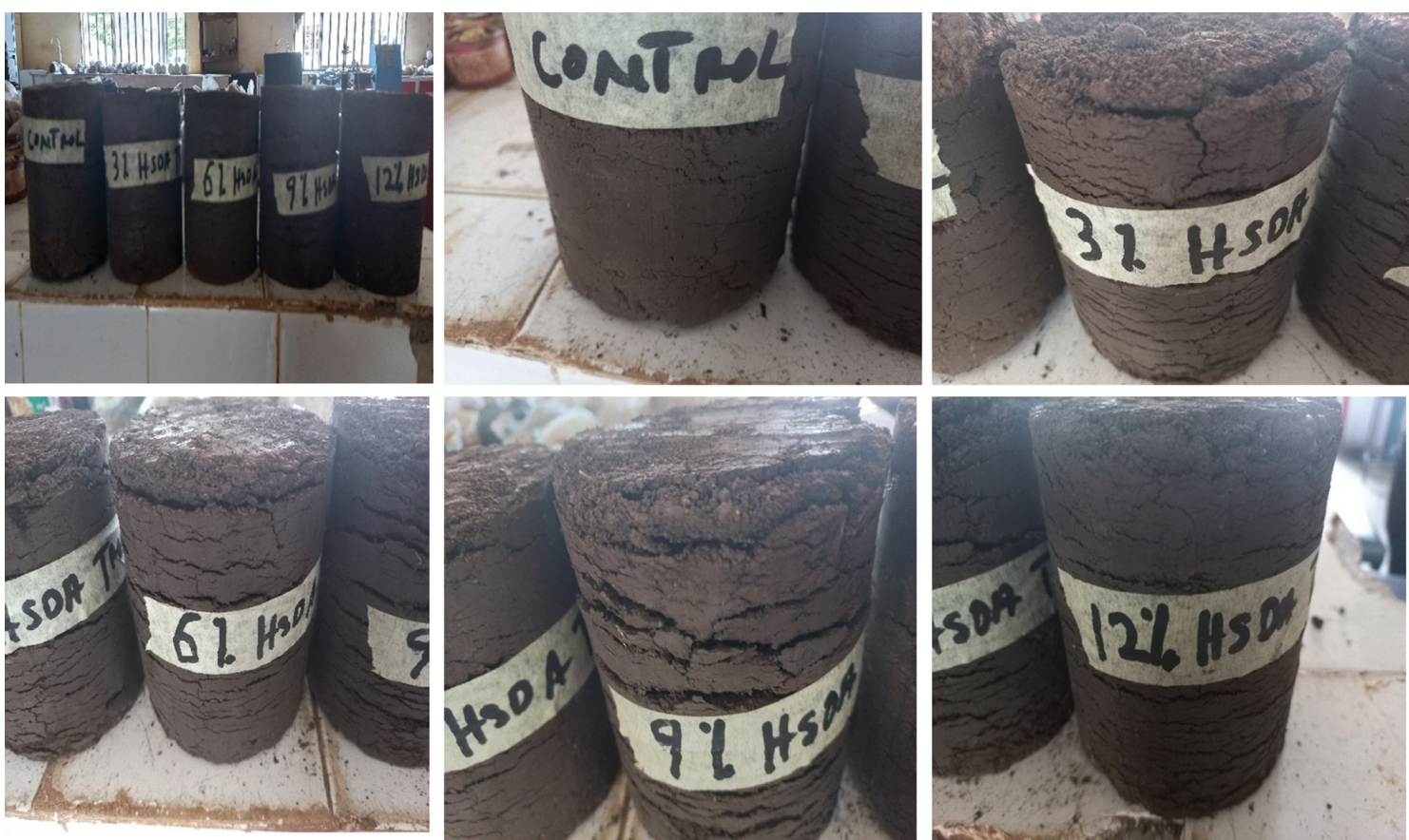

Figure 10: HSDA-treated black cotton soil crack development under drying at $102^{\circ} \mathrm{C}[35]$.

TABLE 3: Basic properties of the BCS.

\begin{tabular}{lccccccccc}
\hline Property & \% Ps 200 & Nmc (\%) & LL (\%) & PL (\%) & PI (\%) & CBR (\%) & MDD & OMC (\%) & SG \\
\hline Value & 59.8 & 18.1 & 51.8 & 16.4 & 37.7 & 7.6 & $1.73 \mathrm{mg} / \mathrm{m}^{3}$ & 11.2 & 2.285 \\
\hline
\end{tabular}


TABLE 4: Performance indicator values for building MLR models for outputs.

\begin{tabular}{|c|c|c|c|c|c|c|c|c|}
\hline & \multicolumn{4}{|c|}{ Train } & \multicolumn{4}{|c|}{ Test } \\
\hline & $\mathrm{R}^{2}$ & VAF & RMSE & MAE & $\mathrm{R}^{2}$ & VAF & RMSE & MAE \\
\hline $\mathrm{CW}$ & 0.854 & 85.386 & 0.558 & 0.450 & 0.884 & 87.686 & 0.603 & 0.495 \\
\hline VS & 0.994 & 99.986 & 0.125 & 0.124 & 0.999 & 99.899 & 0.126 & 0.123 \\
\hline LS & 0.988 & 98.739 & 0.598 & 0.596 & 0.982 & 98.108 & 0.606 & 0.601 \\
\hline
\end{tabular}

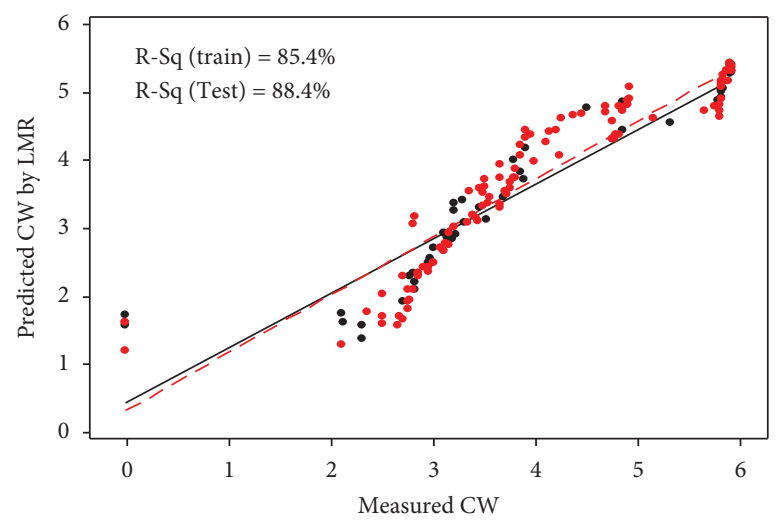

Variable

$\rightarrow$ Test data

$\rightarrow$ Train data

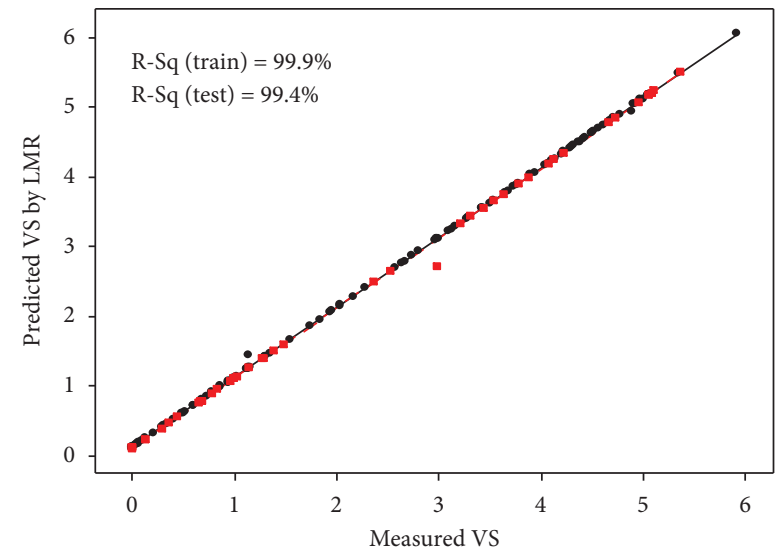

Variable

$\rightarrow$ Train data

$\rightarrow$ Test data

(a)

(b)

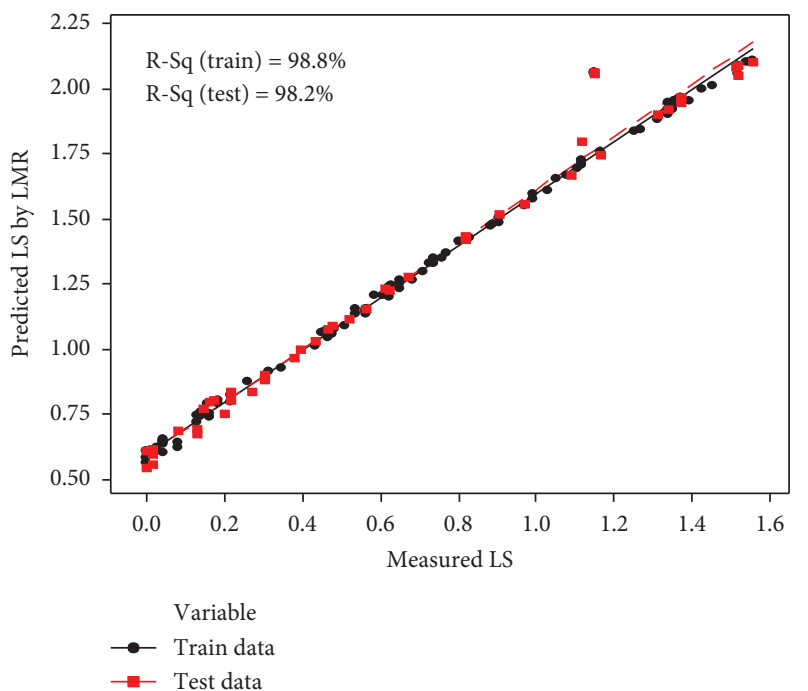

(c)

FIGURE 11: The values of R-squared for MLR models. (a) Crack width (CW), (b) volumetric shrinkage (VS), and (c) linear shrinkage (LS).

TABLE 5: The optimal GWO parameters for outputs. 


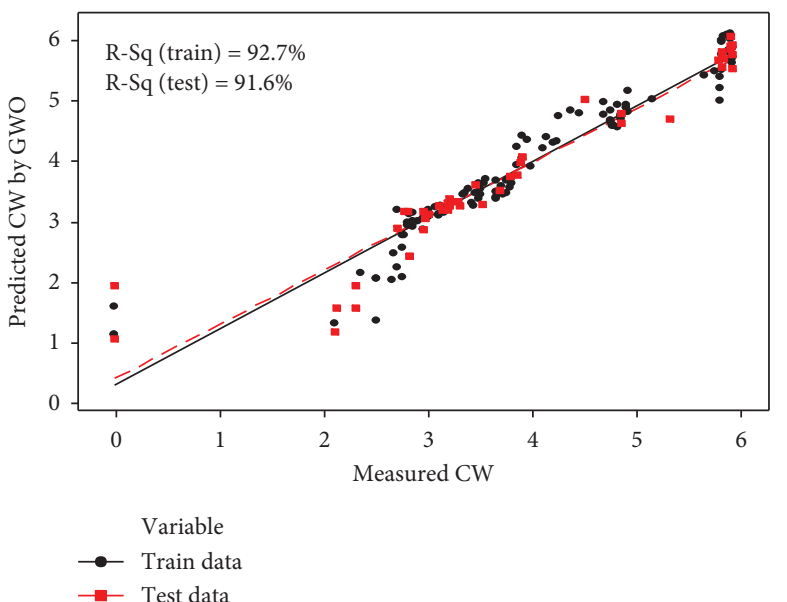

(a)

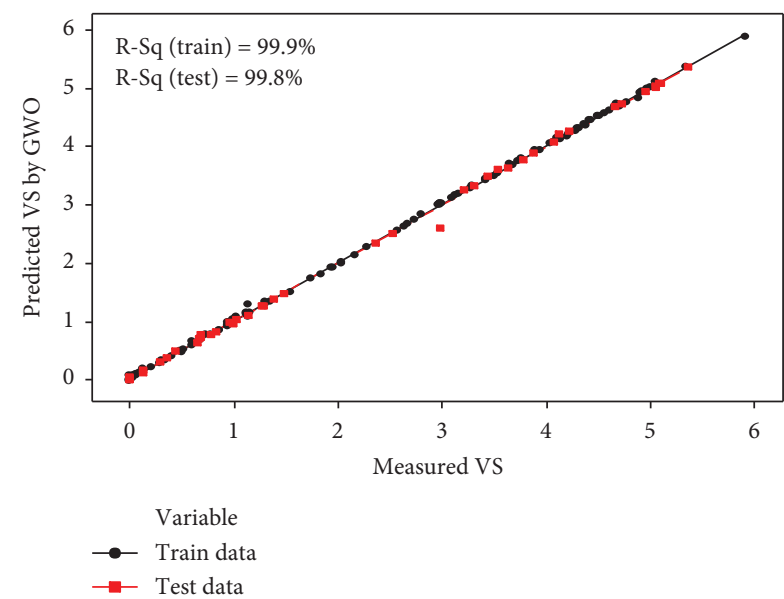

(b)

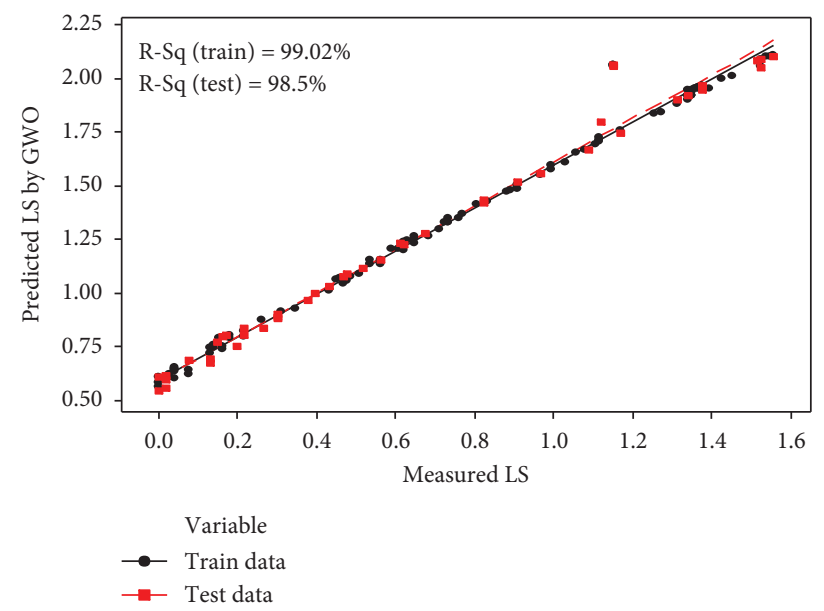

(c)

Figure 12: The values of R-squared for GWO models. (a) Crack width (CW), (b) volumetric shrinkage (VS), and (c) linear shrinkage (LS).

TABLe 6: Performance indicator values for building GWO models for outputs (CW, VS, and LS).

\begin{tabular}{lcccccrrr}
\hline & \multicolumn{2}{c}{ Train } & & & Test & & & \\
& $\mathrm{R}^{2}$ & VAF & RMSE & MAE & $\mathrm{R}^{2}$ & VAF & RMSE & MAE \\
\hline CW & 0.927 & 92.708 & 0.349 & 0.235 & 0.916 & 91.512 & 0.434 & 0.266 \\
VS & 0.999 & 99.972 & 0.029 & 0.021 & 0.999 & 99.866 & 0.067 & 0.034 \\
LS & 0.985 & 98.543 & 0.062 & 0.033 & 0.985 & 98.543 & 0.062 & 0.033 \\
\hline
\end{tabular}

3.5. Predicting with ANN Method. As the last effort for prediction crack width, volumetric shrinkage and linear shrinkage, and artificial neural network method was applied in present study. For this aim, a neural network with feedforward-backpropagation algorithm was considered. By examining different networks with one and two hidden layers containing several neurons; finally, a network with two hidden layers including 11 and 7 neurons in hidden layers, respectively, was obtained as optimum model with the best considered performance indicators for simultaneously predicting of CW, VS, and LS parameters. The schematic structure of the attained ANN model is illustrated in Figure 16.
Table 9 shows the considered parameters of optimal model and the values of considered performance indicators are given in Table 10.

Finally, the relationship between measured values of CW, VS, and LS and predicted values by ANN are presented in Figure 17 for train and test data.

3.6. Discussion. Studies have shown that artificial intelligence approaches have been continuously developed due to the limitations of the laboratory environment, which has convinced researchers that they can use artificial intelligence methods to more accurately evaluate parameters than 


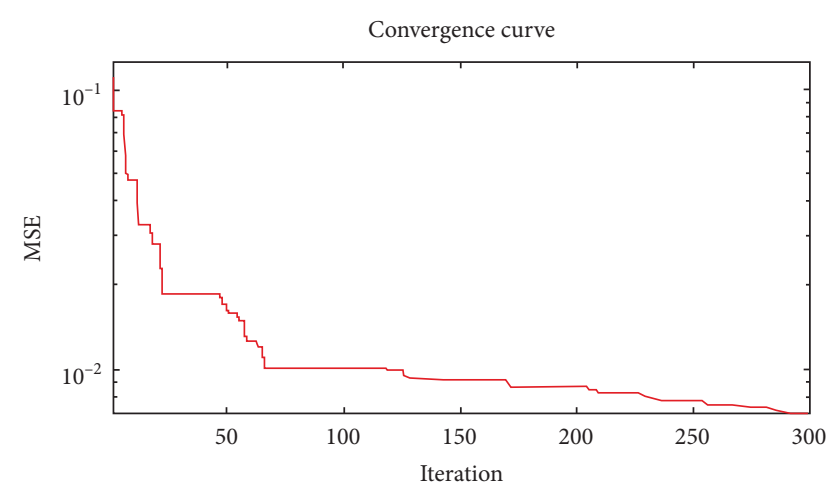

- GWO

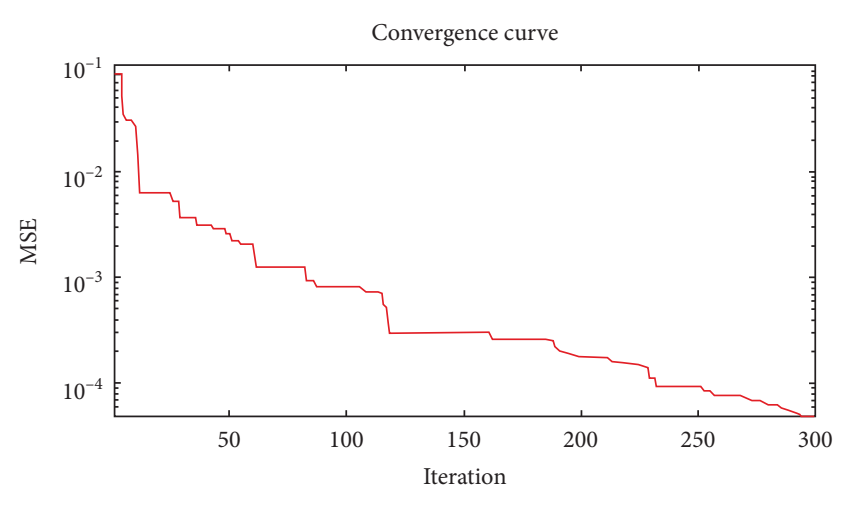

- GWO

(a)

(b)

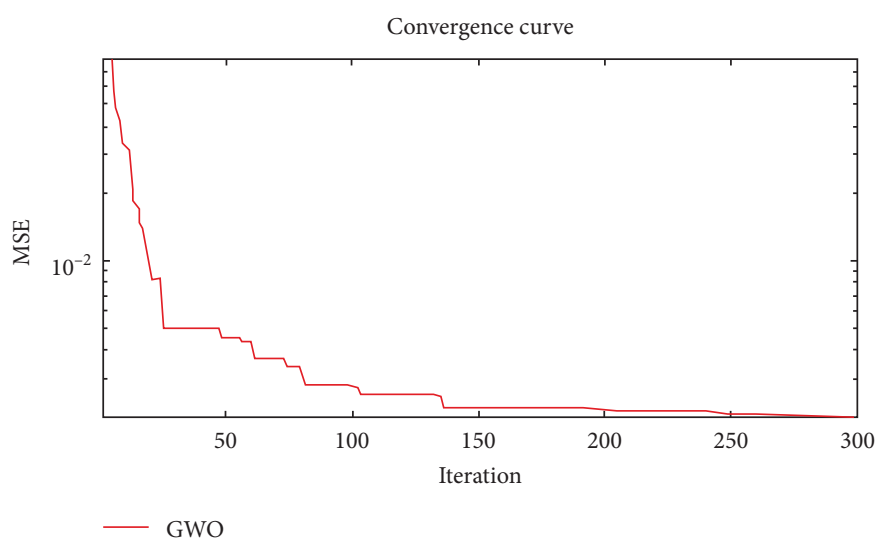

(c)

FIGURE 13: MSE calculated by GWO for predicting. (a) Crack width (CW), (b) volumetric shrinkage (VS), and (c) linear shrinkage (LS).

TABLE 7: The optimal MFO parameters for outputs (CW, VS, and LS).

TABLE 8: Performance indicator values for building MFO models for outputs (CW, VS, and LS).

\begin{tabular}{lcccccrrr}
\hline & \multicolumn{3}{c}{ Train } & & & & Test & \\
& $\mathrm{R}^{2}$ & VAF & RMSE & MAE & $\mathrm{R}^{2}$ & VAF & RMSE & MAE \\
\hline CW & 0.926 & 92.556 & 0.352 & 0.262 & 0.902 & 89.876 & 0.477 & 0.341 \\
VS & 0.994 & 99.432 & 0.131 & 0.106 & 0.989 & 98.981 & 0.186 \\
LS & 0.989 & 98.864 & 0.053 & 0.032 & 0.982 & 98.200 & 0.069 & 0.041 \\
\hline
\end{tabular}

conventional approaches. The main purpose of this paper is to predict crack width (CW), volumetric shrinkage (VS), and linear shrinkage (LS) based on input parameters including HSDA (P), drying (T), Wt of spec. (W), height $(\mathrm{H})$, diameter (D), and volume (V). To develop relationships, data collected from multiple experiments were first used to create a database between input and output data. Then, the best relationships between the outputs and each input were examined by comprehensive statistical analysis. Then, LMR, GWO, MFO, and ANN methods were used to predict CW, VS, and LS. The results of these methods were compared based on the highest $R^{2,} \mathrm{VAF}$ and the lowest values of MAE, RMSE for training and testing. The best values obtained for all methods based on statistical indices are given in Table 11.

According to Table 10, all methods show high accuracy in predicting $\mathrm{CW}, \mathrm{VS}$, and LS values due to the high 


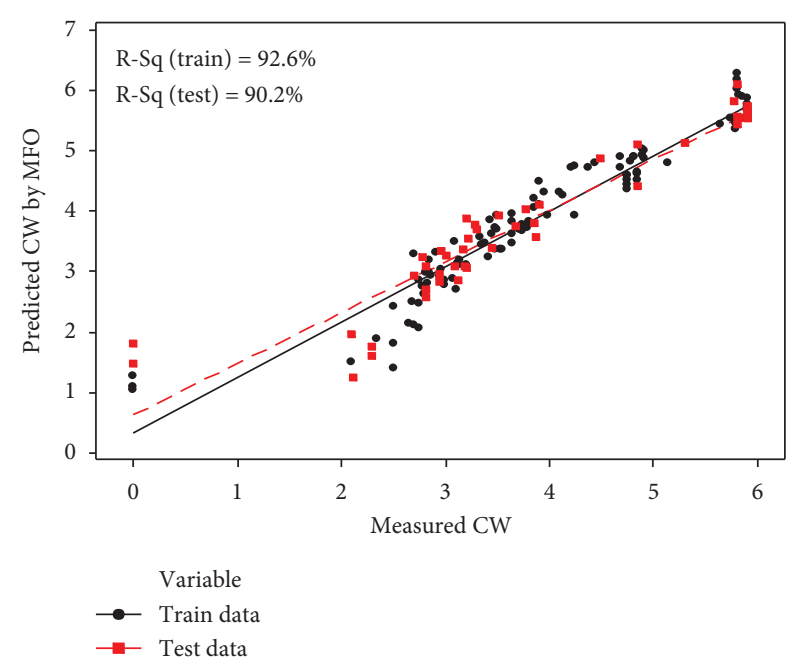

(a)

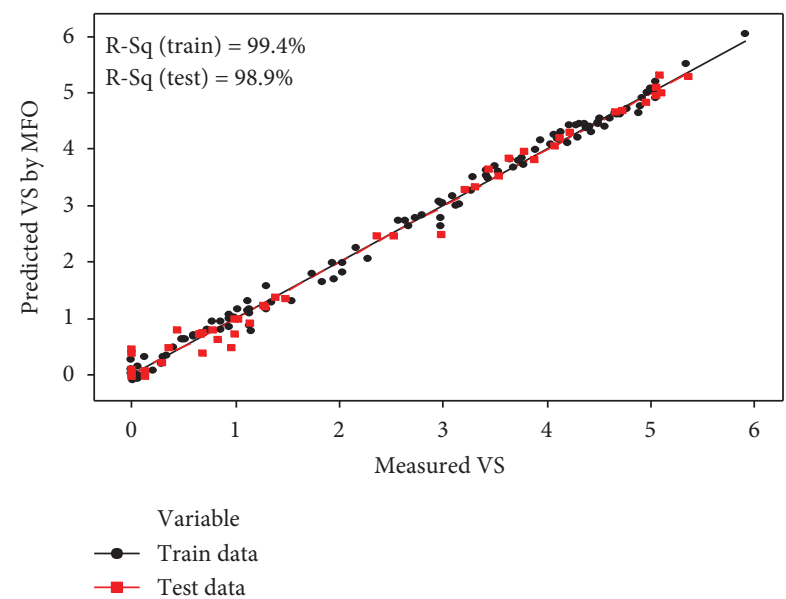

(b)

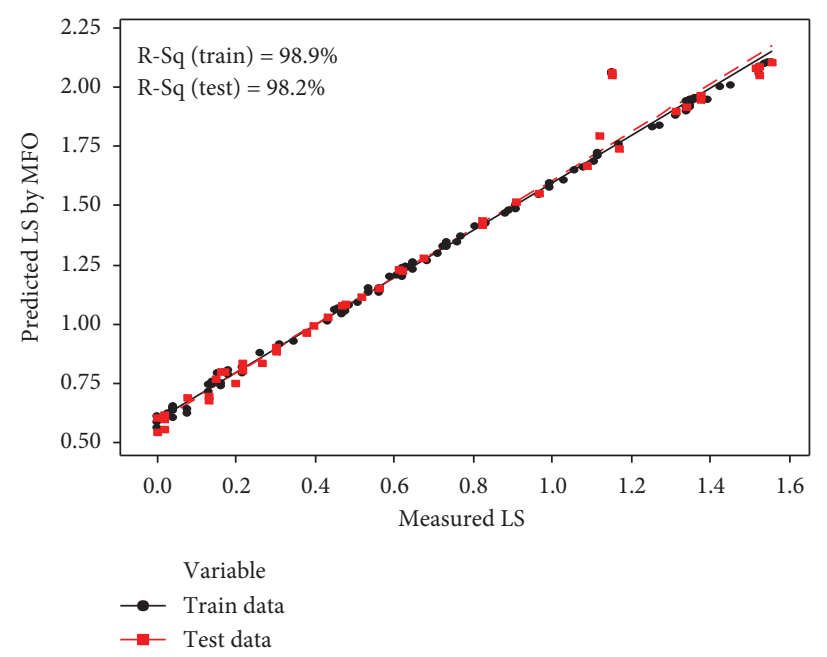

(c)

FIGURE 14: The values of R-squared for MFO models. (a) Crack width (CW), (b) volumetric shrinkage (VS), and (c) linear shrinkage (LS).

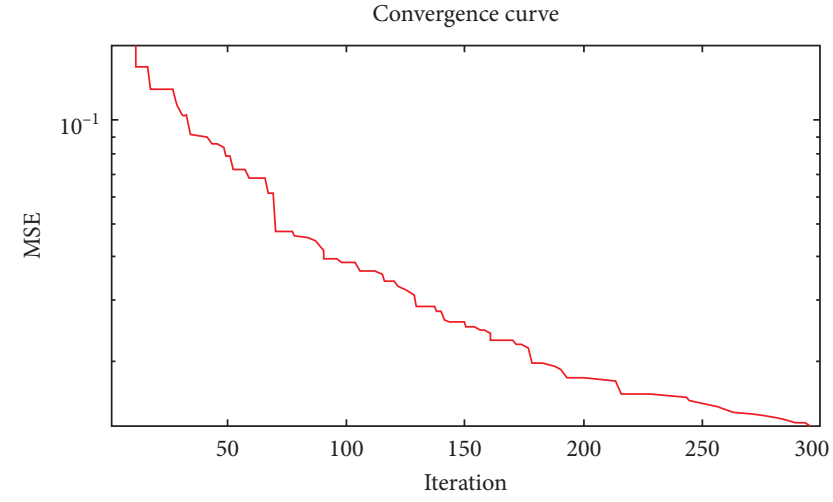

- MFO

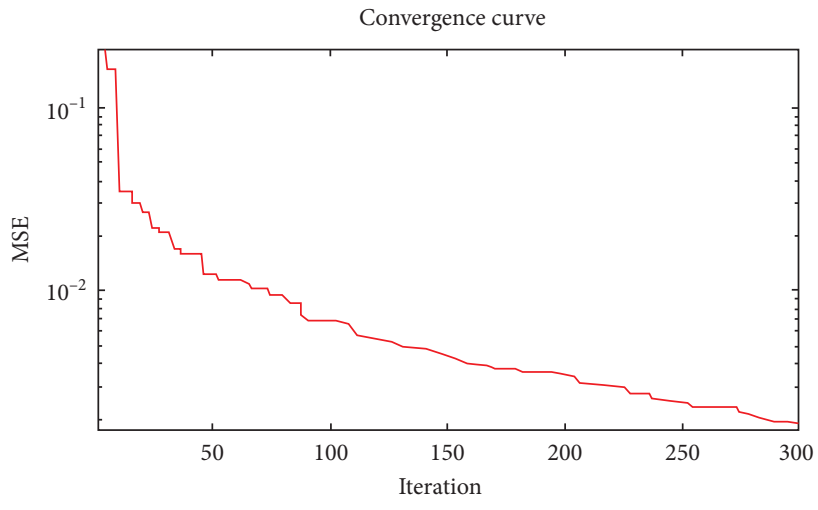

(b)

FIgURE 15: Continued. 


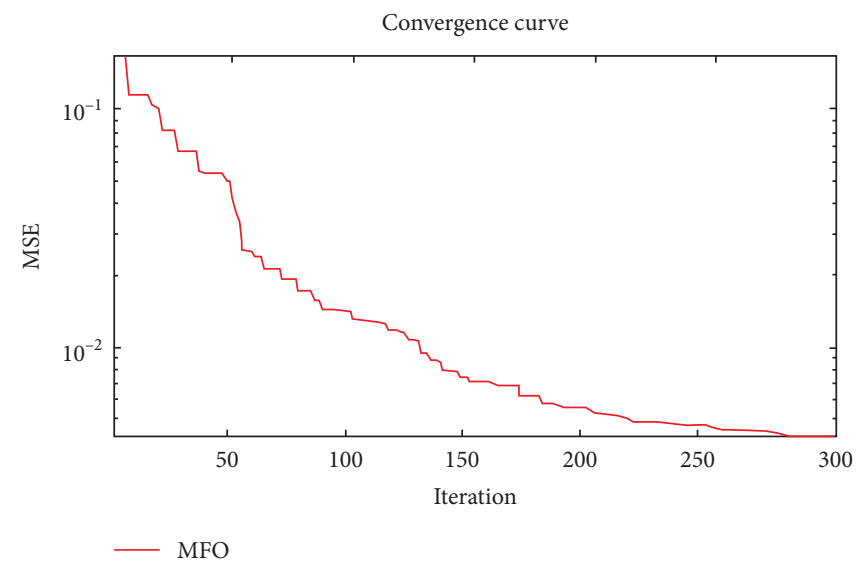

(c)

FIGURE 15: MSE calculated by MFO for predicting. (a) Crack width (CW), (b) volumetric shrinkage (VS), and (c) linear shrinkage (LS).

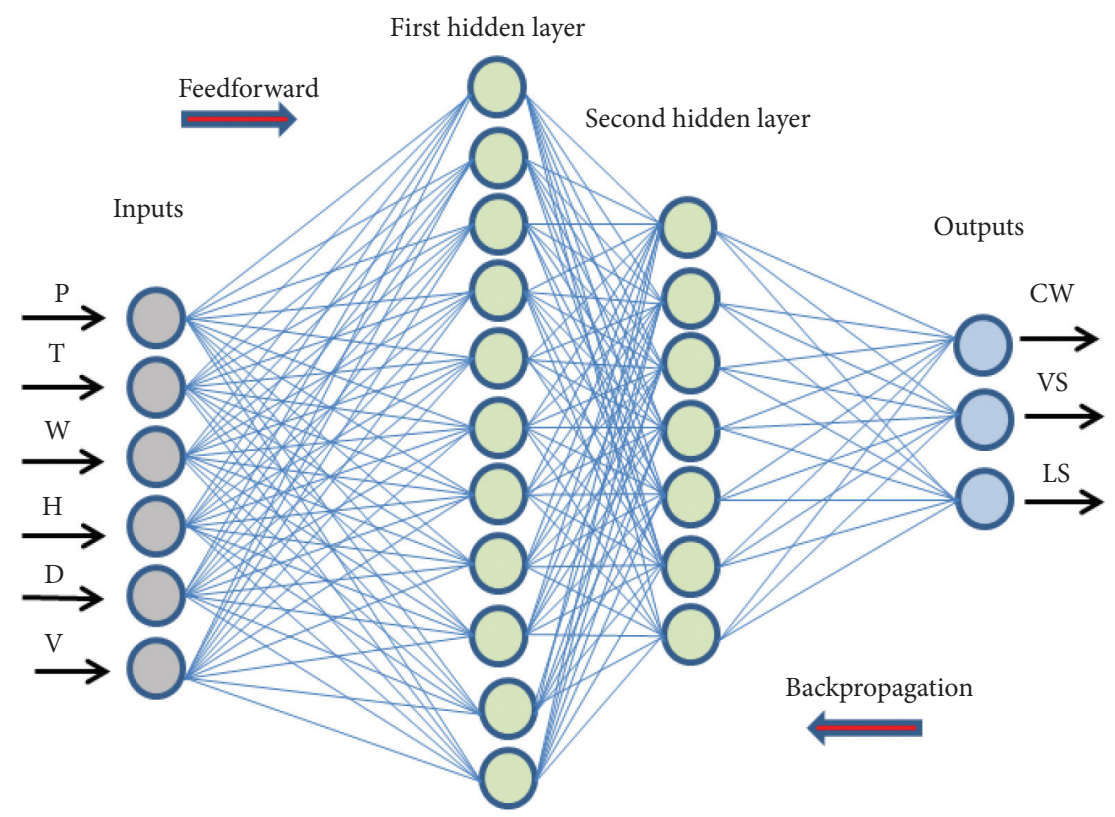

Figure 16: A schematic view of the attained ANN structure in this study.

TABLE 9: The optimal ANN parameters for outputs (CW, VS, and LS).

Parameter

Number of hidden layers

Number of neurons in hidden layers

Type of as transfer function

Type of learning algorithm

Number of train parameter epochs

TABLE 10: Performance indicator values for building ANN models for outputs (CW, VS, and LS).

\begin{tabular}{cccccccrrr}
\hline \multirow{2}{*}{ Model } & \multicolumn{3}{c}{ Train } & \multicolumn{2}{c}{ Test } \\
& & $\mathrm{R}^{2}$ & VAF & RMSE & MAE & $\mathrm{R}^{2}$ & VAF & RMSE & MAE \\
\hline \multirow{3}{*}{ ANN } & CW & 0.999 & 99.982 & 0.017 & 0.012 & 0.961 & 94.868 & 0.354 \\
& VS & 0.999 & 99.988 & 0.020 & 0.011 & 0.999 & 99.860 & 0.070 & 0.032 \\
& LS & 0.999 & 99.997 & 0.003 & 0.002 & 0.999 & 99.468 & 0.038 & 0.014 \\
\hline
\end{tabular}




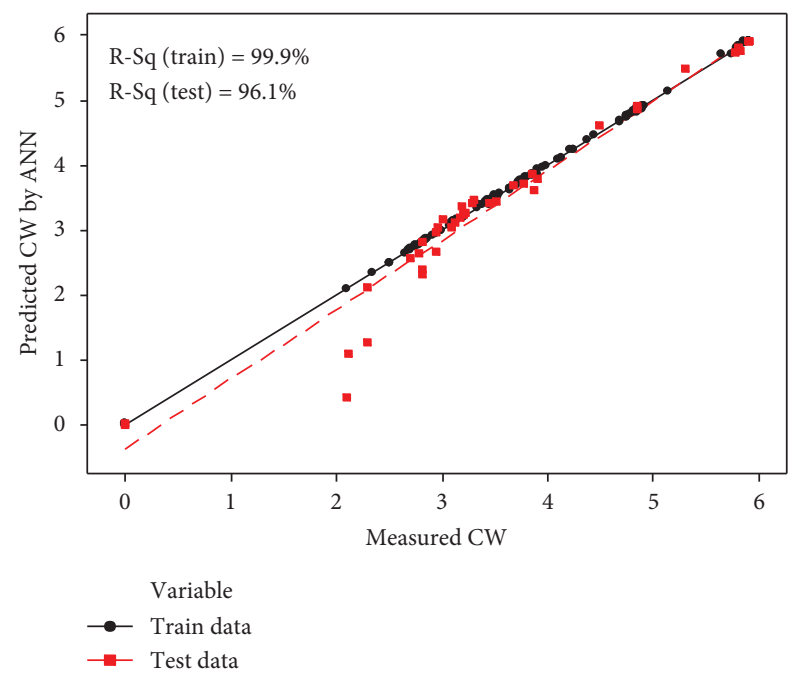

(a)

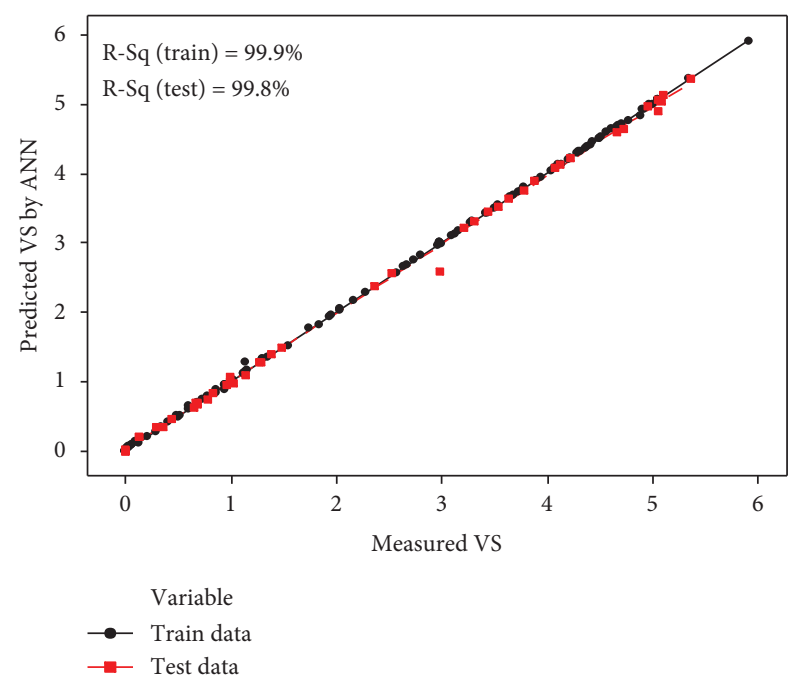

(b)

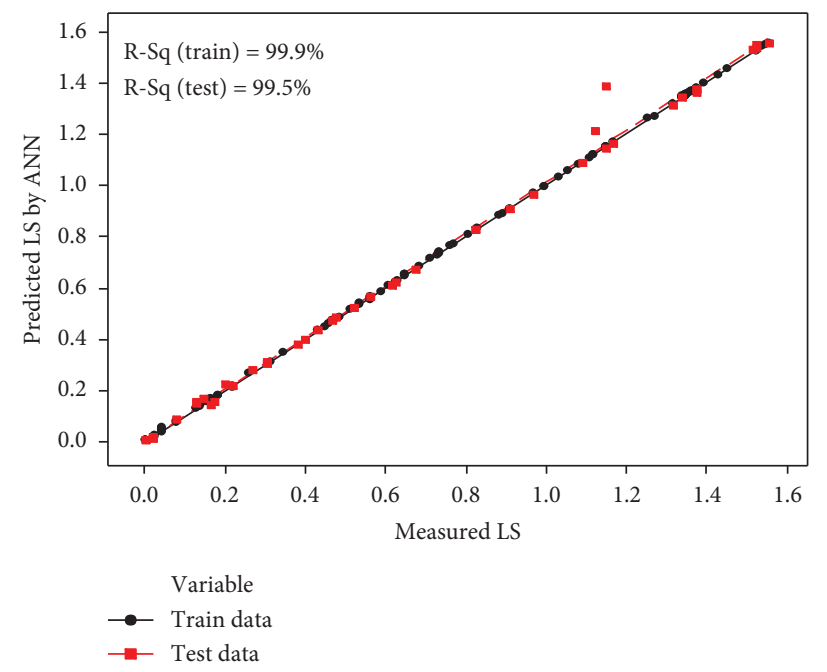

(c)

FIGURE 17: The values of R-squared for ANN models. (a) Crack width (CW), (b) volumetric shrinkage (VS), and (c) linear shrinkage (LS).

TABLE 11: The best predicted values of $R^{2}$, VAF, RMSE, and MAE for predict CW, VS, and LS.

\begin{tabular}{|c|c|c|c|c|c|c|c|c|c|}
\hline \multirow{2}{*}{\multicolumn{2}{|c|}{ Model }} & \multicolumn{4}{|c|}{ Train } & \multicolumn{4}{|c|}{ Test } \\
\hline & & $\mathrm{R}^{2}$ & VAF & RMSE & MAE & $\mathrm{R}^{2}$ & VAF & RMSE & MAE \\
\hline \multirow{3}{*}{ LMR } & CW & 0.854 & 85.386 & 0.558 & 0.450 & 0.884 & 87.686 & 0.603 & 0.495 \\
\hline & VS & 0.994 & 99.986 & 0.125 & 0.124 & 0.999 & 99.899 & 0.126 & 0.123 \\
\hline & LS & 0.988 & 98.739 & 0.598 & 0.596 & 0.982 & 98.108 & 0.606 & 0.601 \\
\hline \multirow{3}{*}{ GWO } & CW & 0.927 & 92.708 & 0.349 & 0.235 & 0.916 & 91.512 & 0.434 & 0.266 \\
\hline & VS & 0.999 & 99.972 & 0.029 & 0.021 & 0.999 & 99.866 & 0.067 & 0.034 \\
\hline & LS & 0.985 & 98.543 & 0.062 & 0.033 & 0.985 & 98.543 & 0.062 & 0.033 \\
\hline \multirow{3}{*}{ MFO } & CW & 0.926 & 92.556 & 0.352 & 0.262 & 0.902 & 89.876 & 0.477 & 0.341 \\
\hline & VS & 0.994 & 99.432 & 0.131 & 0.106 & 0.989 & 98.981 & 0.186 & 0.133 \\
\hline & LS & 0.989 & 98.864 & 0.053 & 0.032 & 0.982 & 98.200 & 0.069 & 0.041 \\
\hline \multirow{3}{*}{ ANN } & CW & 0.999 & 99.982 & 0.017 & 0.012 & 0.961 & 94.868 & 0.354 & 0.164 \\
\hline & VS & 0.999 & 99.988 & 0.020 & 0.011 & 0.999 & 99.860 & 0.070 & 0.032 \\
\hline & LS & 0.999 & 99.997 & 0.003 & 0.002 & 0.999 & 99.468 & 0.038 & 0.014 \\
\hline
\end{tabular}




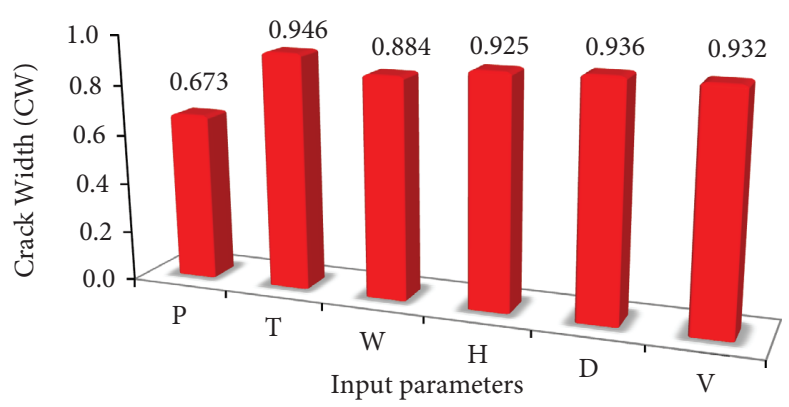

(a)

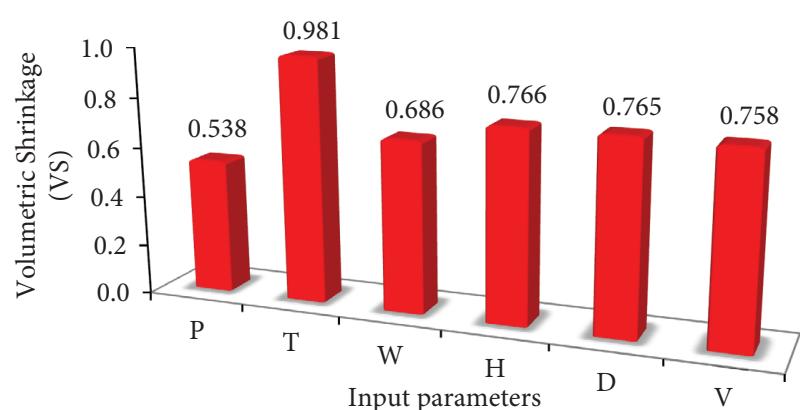

(b)

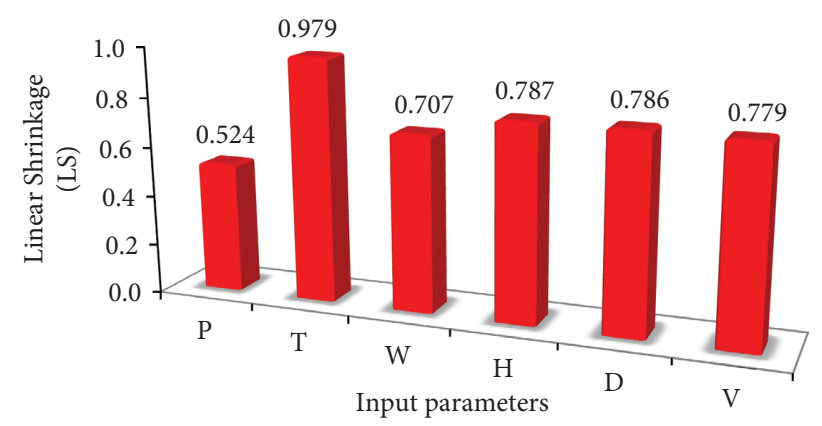

(c)

FIGURE 18: Sensitivity analysis to determine the impact of each data on the output for (a) crack width (CW), (b) volumetric shrinkage (VS), and (c) linear shrinkage (LS).

correlation of the collected data, and if the best models are based on case indices. Consider that ANN had the best performance in predicting all outputs, and then it can be seen that GWO, MFO, and LMR had the best performance in predicting CW, VS, and LS, respectively. This implies that ANN has the more flexibility to be used in predicting the parameters of the desiccation process with high performance indices. However, the three AI techniques have shown the potential to train and predict engineering problems from multiple data points with high performance index of above $90 \%$.

3.7. Sensitivity Analysis. Sensitivity analysis was performed to identify the relative impact of each parameter on output in the mode using the cosine domain method [40]. To apply this method, all of the data pairs were expressed in common $\mathrm{X}$-space. To undertake this technique, all data pairs should be utilized to build a data array $X$ as follows $[3,4,41,42]$ :

$$
X=\left\{x_{1}, x_{2}, x_{3}, \ldots, x_{i}, \ldots, x_{n}\right\} .
$$

Each of the elements, $\mathrm{xi}$, in the data array $X$ is a vector of lengths of $m$; that is,

$$
X=\left\{x_{1} 1, x_{2} 2, x_{3} 3, \ldots, x_{i m}\right\} .
$$

The strength of the relation between the dataset, xi and $\mathrm{xj}$, is presented as follows:

$$
r_{i j}=\frac{\sum_{k=1}^{m} x_{i k} x_{j k}}{\sqrt{\sum_{k=1}^{m} x_{i k}^{2} \sum_{k=1}^{m} x_{i k}^{2}}}
$$

According to Figure 18, which shows the strengths of the relationships (ridge values) between the inputs and outputs of the model, it is concluded that drying (T), diameter (D), volume (V), height $(\mathrm{H})$, Wt of spec. (W), and HSDA (P) had the highest impact on CW, respectively, while for VS and LS, drying (T), diameter (D), height $(\mathrm{H})$, volume (V), Wt of spec. (W), and HSDA (P) had the most impact, respectively.

\section{Conclusions}

Artificial neural network (ANN), gray-wolf, and moth-flame optimization (GWO and MFO) techniques were used to predict the effect of activated sawdust ash (ASDA) on the desiccation properties; crack width (CW), linear shrinkage (LS), and volumetric shrinkage (VS) of a black cotton soil utilized as a subgrade material. From the foregoing, the following can be concluded.

(i) There was appreciable improvement in the shrinkage and crack parameters over the 30-day drying period due to the addition of waste-based ASDA.

(ii) The intelligent model results showed that the three techniques successfully predicted the CW, VS, and LS with a performance accuracy of $96.1 \%, 99.9 \%$, and $99.9 \%$, respectively, for the ANN; $90.2 \%, 98.9 \%$, and $98.2 \%$, respectively, for the MFO; $91.6 \%, 99.9 \%$, and $98.5 \%$, respectively for the GWO, but ANN produce the minimal error in performance outperforming the other techniques. 
(iii) The sensitivity analysis showed that drying period (T) was the most influential of the parameters studied in this model $[43,44]$.

\section{Data Availability}

The data supporting the results of this research has been reported in the paper.

\section{Conflicts of Interest}

The authors declare that they have no conflicts of interest.

\section{Supplementary Materials}

The supplementary file is the tabulation of the multiple data collected from multiple experiments on drying days, weight, height, diameter, volume, crack width, volumetric shrinkage, and linear shrinkage of the hybrid sawdust ash (HSDA) treated black cotton soil (BCS). For a period of 30 days, these parameters were observed and recorded under laboratory conditions. The soil was treated with $3,6,9$, and $12 \%$ by weight of soil of HSDA and specimens were prepared and placed in the oven for drying. (Supplementary Materials)

\section{References}

[1] K. C. Onyelowe, D. Eidgahee-Rezazadeh, H. Jahangir, F. I. Aneke, and L. I. Nwobia, "Forecasting shear parameters, and sensitivity and error analyses of treated subgrade soil," Transportation Infrastructure Geotechnology, 2022a.

[2] K. C. Onyelowe, T. Gnananandarao, and A. M. Ebid, "Estimation of the erodibility of treated unsaturated lateritic soil using support vector machine-polynomial and -radial basis function and random forest regression techniques," Cleaner Materials, vol. 3, Article ID 100039, 2022b.

[3] K. C. Onyelowe and J. Shakeri, "Intelligent prediction of coefficients of curvature and uniformity of hybrid cement modified unsaturated soil with NQF inclusion," Cleaner Engineering and Technology, vol. 4, Article ID 100152, 2021.

[4] K. C. Onyelowe, J. Shakeri, H. Amini-Khoshalann, A. B. Salahudeen, E. E. Arinze, and H. U. Ugwu, "Application of ANFIS hybrids to predict coefficients of curvature and uniformity of treated unsaturated lateritic soil for sustainable earthworks," Cleaner Materials, vol. 1, Article ID 100005, 2021.

[5] D. C. Montgomery and E. A. Peck, Introduction to Linear Regression AnalysisWiley, New York, NY, USA, 1992.

[6] M. Rezaei and M. Asadizadeh, "Predicting unconfined compressive strength of intact rock using new hybrid intelligent models," Journal of Mining and Environment, vol. 11, no. 1, pp. 231-246, 2020.

[7] V. K. Chawla, A. K. Chanda, and S. Angra, "The scheduling of automatic guided vehicles for the workload balancing and travel time minimi-zation in the flexible manufacturing system by the nature-inspired algorithm," Journal of Project Management, vol. 4, no. 1, pp. 19-30, 2019.

[8] S. Emami, Y. Choopan, and F. Salmasi, "Presentation of a method based on gray wolf optimizer and imperialist competitive algorithms in optimal operation of dam reservoir," Amirkabir Journal of Civil Engineering, vol. 52, no. 5, p. 1, 2018.
[9] A. Goli, H. K. Zare, R. Tavakkoli-Moghaddam, and A. Sadeghieh, "An improved artificial intelligence based on gray wolf optimization and cultural algorithm to predict demand for dairy products: a case study," International Journal of Interactive Multimedia and Artificial Intelligence, vol. 5, no. 6, pp. 15-22, 2019.

[10] Y. Choopan and S. Emami, "Optimal operation of dam reservoir using gray wolf optimizer algorithm (case study: urmia shaharchay dam in Iran)," Journal of Soft Computing in Civil Engineering, vol. 3, no. 3, pp. 47-61, 2019.

[11] E. Emary, W. Yamany, A. E. Hassanien, and V. Snasel, "Multiobjective gray-wolf optimization for attribute reduction," Procedia Computer Science, vol. 65, pp. 623-632, 2015.

[12] C. Xu, M. N. Amar, M. A. Ghriga, H. Ouaer, X. Zhang, and M. Hasanipanah, "Evolving support vector regression using Grey Wolf optimization; forecasting the geomechanical properties of rock," Engineering with Computers, pp. 1-15, 2020.

[13] Z. Yu, X. Shi, J. Zhou et al., "Prediction of blast-induced rock movement during bench blasting: use of gray wolf optimizer and support vector regression," Natural Resources Research, vol. 29, no. 2, pp. 843-865, 2020.

[14] E. Emary, H. M. Zawbaa, and C. Grosan, "Experienced gray wolf optimization through reinforcement learning and neural networks," IEEE Transactions on Neural Networks and Learning Systems, vol. 29, no. 3, pp. 681-694, 2017.

[15] A. Dehghanbanadaki, M. Khari, S. T. Amiri, and D. J. Armaghani, "Estimation of ultimate bearing capacity of driven piles in $c-\varphi$ soil using MLP-GWO and ANFIS-GWO models: a comparative study," Soft Computing, vol. 25, no. 5, pp. 4103-4119, 2021.

[16] A. R. Tavakolpour-Saleh, S. H. Zare, and H. Badjian, "Multiobjective optimization of Stirling heat engine using gray wolf optimization algorithm," International Journal of Engineering-Transactions C: Aspects, vol. 30, no. 6, pp. 321-329, 2017.

[17] S. Mirjalili, "Moth-flame optimization algorithm: a novel nature-inspired heuristic paradigm," Knowledge-Based Systems, vol. 89, pp. 228-249, 2015a.

[18] M. Shehab, L. Abualigah, H. Al Hamad, H. Alabool, M. Alshinwan, and A. M. Khasawneh, "Moth-flame optimization algorithm: variants and applications," Neural Computing \& Applications, vol. 32, no. 14, pp. 9859-9884, 2020a.

[19] G.-Q. Lin, L.-L. Li, M.-L. Tseng, H.-M. Liu, D.-D. Yuan, and R. R. Tan, "An improved moth-flame optimization algorithm for support vector machine prediction of photovoltaic power generation," Journal of Cleaner Production, vol. 253, Article ID 119966, 2020.

[20] R. Barham, A. Sharieh, and A. Sleit, "Moth flame optimization based on golden section search and its application for link prediction problem," Modern Applied Science, vol. 13, no. 1, pp. 10-27, 2018.

[21] R. Barham, A. Sharieh, and A. Sleit, "Multi-moth flame optimization for solving the link prediction problem in complex networks," Evolutionary Intelligence, vol. 12, no. 4, pp. 563-591, 2019.

[22] I. Tumar, Y. Hassouneh, H. Turabieh, and T. Thaher, "Enhanced binary moth flame optimization as a feature selection algorithm to predict software fault prediction," IEEE Access, vol. 8, pp. 8041-8055, 2020.

[23] R. K. Singh, S. Gangwar, D. K. Singh, and V. K. Pathak, "A novel hybridization of artificial neural network and mothflame optimization (ANN-MFO) for multi-objective optimization in magnetic abrasive finishing of aluminium 6060," 
Journal of the Brazilian Society of Mechanical Sciences and Engineering, vol. 41, no. 6, pp. 1-19, 2019.

[24] R. Aghaie and M. Farshad, "Maximum power point tracker for photovoltaic systems based on moth-flame optimization considering partial shading conditions," Journal of Operation and Automation in Power Engineering, vol. 7, no. 2, pp. 176-186, 2019.

[25] C. Chen, X. Wang, C. Wu, M. Mafarja, H. Turabieh, and H. Chen, "Soil erosion prediction based on moth-flame optimizer-evolved kernel extreme learning machine," Electronics, vol. 10, no. 17, p. 2115, 2021.

[26] H. Nguyen and X.-N. Bui, "Predicting blast-induced air overpressure: a robust artificial intelligence system based on artificial neural networks and random forest," Natural Resources Research, vol. 28, no. 3, pp. 893-907, 2019.

[27] A. Shojaeian and M. Asadizadeh, "Prediction of surface tension of the binary mixtures containing ionic liquid using heuristic approaches; an input parameters investigation," Journal of Molecular Liquids, vol. 298, Article ID 111976, 2020.

[28] D. Jahed Armaghani, M. Hasanipanah, and E. Tonnizam Mohamad, "A combination of the ICA-ANN model to predict air-overpressure resulting from blasting," Engineering with Computers, vol. 32, no. 1, pp. 155-171, 2016c.

[29] M. Monjezi, A. Bahrami, A. Y. Varjani, and A. R. Sayadi, "Prediction and controlling of flyrock in blasting operation using artificial neural network," Arabian Journal of Geosciences, vol. 4, no. 3-4, pp. 421-425, 2011.

[30] H. Nikafshan Rad, I. Bakhshayeshi, W. A. Wan Jusoh, M. M. Tahir, and L. K. Foong, "Prediction of flyrock in mine blasting: a new computational intelligence approach," Natural Resources Research, vol. 29, no. 2, pp. 609-623, 2020.

[31] K. M. Mendez, D. I. Broadhurst, and S. N. Reinke, "The application of artificial neural networks in metabolomics: a historical perspective," Metabolomics, vol. 15, no. 11, p. 142, 2019.

[32] X. Fan, L. Wang, and S. Li, "Predicting chaotic coal prices using a multi-layer perceptron network model," Resources Policy, vol. 50, pp. 86-92, 2016.

[33] X. Lu, M. Hasanipanah, K. Brindhadevi, H. Bakhshandeh Amnieh, and S. Khalafi, "ORELM: a novel machine learning approach for prediction of flyrock in mine blasting," Natural Resources Research, vol. 29, no. 2, pp. 641-654, 2020.

[34] M. S. Ashraf, Z. Ghouleh, and Y. Shao, "Production of ecocement exclusively from municipal solid waste incineration residues," Resources, Conservation and Recycling, vol. 149, pp. 332-342, 2019.

[35] K. C. Onyelowe and T. Usungedo, "Microstructure, 3chemical moduli (3CM) and micro-spectral analyses of HSDA-treated black cotton soil for sustainable subgrade construction," Materials Today Proceedings, 2021.

[36] ASTM, Standard Specification for Coal Fly Ash and Raw or Calcined Natural Pozzolan for Use in Concrete, American Society for Testing Materials, West Conshohocken, PA, USA, 2019.

[37] Bs 8615-1, Specification for Pozzolanic Materials for Use with Portland cement Natural Pozzolana and Natural Calcined Pozzolana, British Standard International, London, England, 2019.

[38] Bs 1377 - 2, Methods of Testing Soils for Civil Engineering Purposes, Vol. 3, British Standard Institute, , London, England, 1990.

[39] Bs 1924, Methods of Tests for Stabilized Soil, British Standard Institute, London, England, 1990.
[40] Y. Yang and Q. Zhang, "A hierarchical analysis for rock engineering using artificial neural networks," Rock Mechanics and Rock Engineering, vol. 30, no. 4, pp. 207-222, 1997.

[41] R. S. Faradonbeh, D. J. Armaghani, M. Z. Abd Majid et al., "Prediction of ground vibration due to quarry blasting based on gene expression programming: a new model for peak particle velocity prediction," International journal of Environmental Science and Technology, vol. 13, no. 6, 2016.

[42] K. Sayevand, H. Arab, and S. B. Golzar, "Development of imperialist competitive algorithm in predicting the particle size distribution after mine blasting," Engineering with Computers, vol. 34, no. 2, pp. 329-338, 2018. 